Florida International University FIU Digital Commons

\title{
An Institutional, Socio-economic, and Legal Analysis of Fisheries Co-management and Regulation in the Gulf of Nicoya, Costa Rica
}

Alejandro J. Garcia Lozano

alejgarcialozano@gmail.com

DOI: $10.25148 /$ etd.FI14071174

Follow this and additional works at: https://digitalcommons.fiu.edu/etd

\section{Recommended Citation}

Garcia Lozano, Alejandro J., "An Institutional, Socio-economic, and Legal Analysis of Fisheries Co-management and Regulation in the Gulf of Nicoya, Costa Rica" (2014). FIU Electronic Theses and Dissertations. 1539.

https://digitalcommons.fiu.edu/etd/1539 


\title{
FLORIDA INTERNATIONAL UNIVERSITY \\ Miami, Florida
}

\section{AN INSTITUTIONAL, SOCIO-ECONOMIC, AND LEGAL ANALYSIS OF FISHERIES CO-MANAGEMENT AND REGULATION IN THE GULF OF NICOYA, COSTA RICA}

\author{
A thesis submitted in partial fulfillment of \\ the requirements for the degree of \\ MASTER OF SCIENCE \\ in \\ ENVIRONMENTAL STUDIES
}

by

Alejandro García Lozano 
To: Interim Dean Michael R. Heithaus College of Arts and Sciences

This thesis, written by Alejandro García Lozano, and entitled An Institutional, Socioeconomic, and Legal Analysis of Fisheries Co-management and Regulation in the Gulf of Nicoya, Costa Rica, having been approved in respect to style and intellectual content, is referred to you for judgment.

We have read this thesis and recommend that it be approved.

David B. Bray

Mahadev G. Bhat

Joel T. Heinen, Major Professor

Date of Defense: June 30, 2014

The thesis of Alejandro García Lozano is approved.

Interim Dean Michael R. Heithaus College of Arts and Sciences

Dean Lakshmi N. Reddi University Graduate School

Florida International University, 2014 


\section{ACKNOWLEDGMENTS}

This work would not have been possible without the support of several important individuals and organizations. I want to thank my advisor Dr. Joel Heinen for his input, perspective, financial support, and his trust in my ability to conduct this research independently. I would also like to thank my other committee members: Dr. David Bray, for guiding me as I navigated the vast literature on the commons, as well as for his valuable and constructive criticism; and Dr. Bhat, for greatly sharpening the skills I needed to conduct critical and thoughtful policy analysis.

I have immense appreciation for members of CoopeSoliDar R.L., especially Vivienne Solís Rivera, members of CoopeTárcoles R.L. and Consorcio PorLaMar R.L., members of Fundación MarViva, and all the fishers, community members, and other informants that agreed to participate in this project. I want to thank the Adanis family for giving me a second home in Tárcoles, as well as my parents, my sister, and chosen family in Miami for keeping me sane. José Villar, you have been the best friend anyone could hope for and you have been an essential catalyst for my growth. Thank you for providing your expertise in linguistics and helping to review the legal data.

Finally, I would like to thank Florida International University and the Department of Earth and Environment for giving me this opportunity and supporting me in this important stage of my career. The experiences I have had during my teaching assistantship in the Department of Earth and Environment have been invaluable. I have also received financial support from the Graduate Minority Opportunities Program at FIU and the Great Lakes National Scholarship. 


\author{
ABSTRACT OF THE THESIS \\ AN INSTITUTIONAL, SOCIO-ECONOMIC, AND LEGAL ANALYSIS OF \\ FISHERIES CO-MANAGEMENT AND REGULATION IN THE \\ GULF OF NICOYA, COSTA RICA \\ by
}

Alejandro García Lozano

Florida International University, 2014

Miami, Florida

Professor Joel T. Heinen, Major Professor

Marine Areas for Responsible Artisanal Fishing (AMPR) have emerged as a new model for co-managing small-scale fisheries in Costa Rica, one that involves collaboration between fishers, government agencies and NGOs. This thesis aims to examine the context for collective action and co-management by small-scale fishers; evaluate the design, implementation, and enforcement of AMPRs; and conduct a linguistic analysis of fisheries legislation. The present work relies on the analysis of several types of qualitative data, including interviews with 23 key informants, rapid rural assessments, and legal documents. Findings demonstrate the strong influence of economic factors for sustaining collective action, as well as the importance of certain types of external organizations for community development and co-management. Additionally, significant enforcement gaps and institutional deficiencies were identified in the work of regulating agencies. Legal analysis suggests that mechanisms for government accountability are unavailable and that legal discourse reflects some of the most salient problems in management. 


\section{TABLE OF CONTENTS}

CHAPTER

PAGE

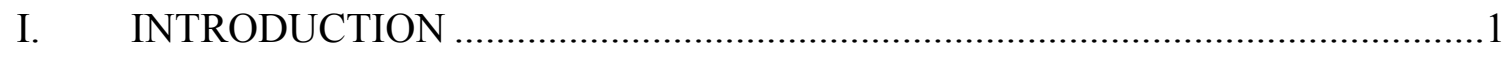

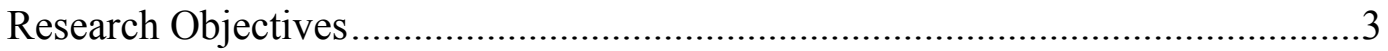

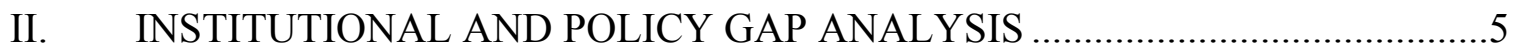

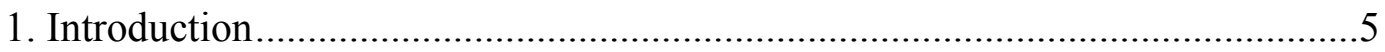

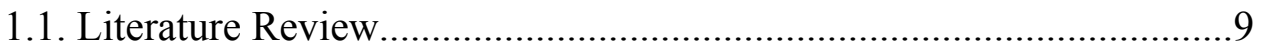

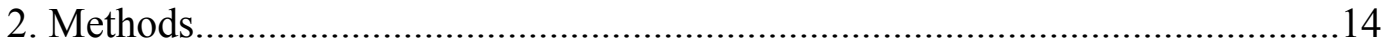

2.1. Theoretical Framework ..................................................................14

2.2. Study Site Description: Two AMPRs in the Gulf of Nicoya ..............20

2.3. Key Informant And Informal Interviews ............................................23

2.4. Qualitative Data Analysis ..............................................................26

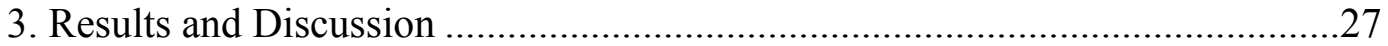

3.1. Socio-Economic and Institutional Context For Collective Action and AMPRs ……..................................................................27

3.2. Incentives For Collective Action In Tárcoles ......................................30

3.2.1. The Role of an External Organization:

CoopeSoliDar R.L......................................................................34

3.2.2. Additional Benefits of the Cooperative ................................38

3.2.3. Livelihood Strategies ............................................................. 41

3.3. Collective Action and External Organizations in the

Isla Chira AMPR.

3.4. Policy Gap Analysis: Ostrom's Design Principles ............................49

3.4.1. Additional Problems Identified..........................................59

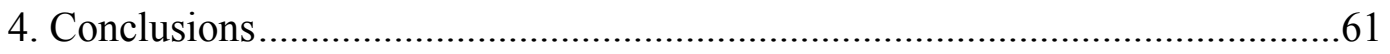

III. LEGAL ANALYSIS: INSTITUTIONAL GRAMMAR TOOL ...........................64

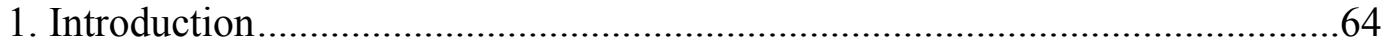

1.1. The Institutional Grammar Tool ......................................................68

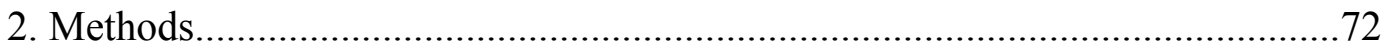

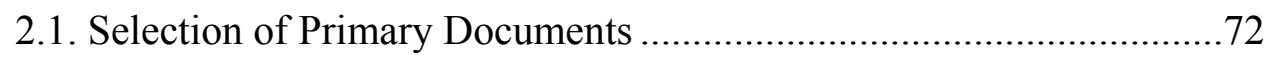

2.2. Analysis....................................................................................72

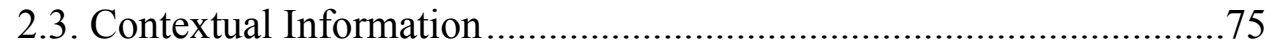

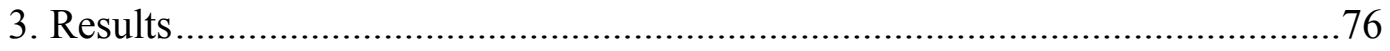

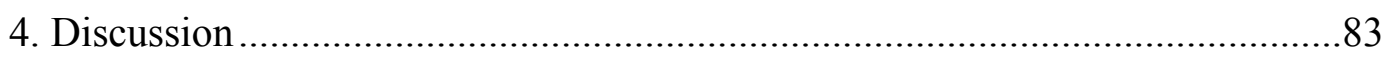

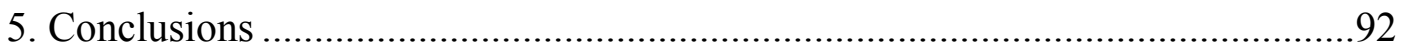

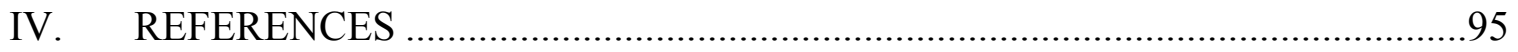

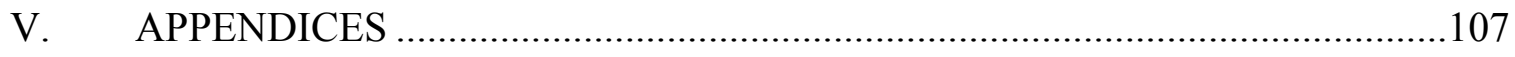




\section{LIST OF TABLES}

TABLE

PAGE

Table 1. Important factors for fisheries policy analysis using the IAD framework .16

Table 2. Design principles for enduring CPR governance regimes ..............................18

Table 3. Definitions and examples of IGT syntax elements ..................................... 70

Table 4. Grouping and modal examples of attribute components for nested analysis ......75

Table 5. Frequency of institutional statements identified ........................................

Table 6. Frequency of unique syntax components identified in coding .........................77

Table 7. Prescriptive types and frequencies of deontic operators.................................77

Table 8. Sample norms with identified ABDICO syntax components. ...........................79

Table 9. Nested analysis of attribute groups by modal deontic operators ........................81 


\section{INTRODUCTION}

In Costa Rica, dominant strategies for the management and conservation of marine-coastal resources involve top-down regulation by the Costa Rican Institute of Fisheries and Aquaculture (INCOPESCA) and the creation of marine protected areas (MPA) managed by the Ministry of Environment and Energy (MINAE). As the state's sole and independent agency for the regulation of fisheries, INCOPESCA has extensive regulatory competencies and responsibilities, but its deficiencies have been widely noted in the academic literature (e.g., Alpízar 2006; Araya 2012) and public outlets (e.g., Solano 2014). In addition, there are 20 MPAs in Costa Rica, most of which are adjoined to terrestrial protected areas within the nation's extensive national park system, but cover only approximately $0.9 \%$ of the nations extensive exclusive economic zone (EEZ;

Alvarado et al. 2012). Protected areas are designed for preserving biodiversity and restoring wildlife populations, but tend to have negative consequences for vulnerable social groups, such as displacement from resources that sustain rural livelihoods. Because MPAs result in the reallocation of various forms of property rights, the impacts can be wide-ranging, from debilitated local governance rights to decreased indicators of health, economic well-being, education, and social capital (Mascia and Claus 2008).

Case studies from Central America and Costa Rica more specifically suggest that there may be conflicts of interest in the management of MPAs, which preferentially benefits profitable sectors (e.g., touristic sport fishing), and that there are a number of underlying social problems left to address (e.g., poverty, education), all of which preclude participatory and inclusive management (Solís Rivera et al. 2012). Additionally, communities generally do not feel included or represented in decision-making for the 
management of MPAs in Costa Rica (Solís Rivera et al. 2012). In recent years, Costa Rica has adopted two new MPA classifications (i.e., Marine Reserve and Marine Management Area; Corella et al. 2011) that permit low-impact artisanal fishing, which reflects values of social sustainability generally recognized in fisheries legislation, as well as a trend towards recognizing small-scale fishers' rights. However, no Marine Reserves have yet been established and only one Marine Management Area has been designated to protect the marine area surrounding Cocos Island National Park (Salas et al. 2012), making it difficult to assess their benefits at the present time.

In recent years, several artisanal fishing organizations have worked to gain government recognition and counteract the impacts of poorly regulated commercial fishing, often in collaboration with non-governmental organizations (NGOs). For instance, a marketing cooperative of fishers in the coastal Pacific village of Tárcoles, CoopeTárcoles R.L., have developed a relationship of associativity with CoopeSoliDar R.L., a cooperative that seeks to promote workers' self-management and solidarity in rural communities. Their work with INCOPESCA has been instrumental for developing a novel and legally recognized model of marine spatial planning known as Marine Areas for Responsible Fishing (Área Marina de Pesca Responsible, AMPR). The AMPR is a co-management approach that recognizes the contributions of artisanal fishers in decision-making and facilitates the devolution of rights and responsibilities to communities. Several AMPRs have been created since the enabling legislation in 2009, but implementation remains at varying levels of progress. 


\section{Research Objectives}

In light of the potential benefits of AMPRs as a mechanism for improving management, conservation, and social sustainability, this research has several objectives to be addressed in two separate papers. In the first paper of the thesis (Chapter II), a primary objective is to describe the context in which co-management and communitybased conservation strategies are developing in this region. More specifically, I seek to determine how legal, institutional, and socio-economic factors interact to influence decision-making by stakeholders, as well as how they influence collective action. Additionally, because the AMPR is a relatively new management model, the other major objective for this paper is to identify its benefits, as well as problems or gaps in design, implementation, and enforcement. To achieve the proposed objectives, the current study relies on interviews with key informants, ethnographic observation, and the collection and review of pertinent documents (e.g., government reports, legislation, gray literature, academic literature). In a general sense, the aim of the first paper is to gain a greater understanding of the conditions that influence fishery regulation in Costa Rica in order to generate recommendations for the future management of AMPRs. Some of the research questions guiding the present work include:

- What kinds of incentives exist for collective action among artisanal fishers in Costa Rica, especially through cooperatives and fishing associations?

- What incentives do fishing organizations have for participating in conservation and co-management of fishery resources?

- What impact do NGOs as outside organizations have on social aspects of sustainability and conservation in the Gulf of Nicoya? 
- How do cross-scale linkages and existing legal restrictions influence management and conservation in this region?

- What problems, conflicts, or obstacles exist in the implementation of AMPRs?

The second paper (Chapter III) addresses an additional research question. As previously mentioned, some resource users (i.e., artisanal fishers) are disenfranchised from the decision-making processes that govern MPAs and fisheries regulation. In my analysis of qualitative data from interviews, participants' responses suggested that rules and regulations are disproportionately aimed at small-scale fishers, and that government agencies are not accountable to some users. Accordingly, the objective of the second paper is to determine whether reported biases in regulation are reflected in the established legislative framework and legal discourse. The institutional grammar tool (IGT) developed by Crawford and Ostrom (1995), and further refined by Basurto et al. (2010) and Siddiki et al. (2012), is a method of linguistic analysis that is useful for studying complex policies and their influence as tools for prescribing human behavior (Basurto et al. 2010). For the second paper, I analyzed two pieces of Costa Rican legislation: the major law for managing fisheries and aquaculture and an executive decree issued to regulate the creation and administration of AMPRs. 


\author{
II. INSTITUTIONAL AND POLICY GAP ANALYSIS: \\ Evaluating Community-Based Co-management in Two Small-Scale \\ Fisheries in the Gulf of Nicoya, Costa Rica
}

\title{
1. Introduction
}

In Costa Rica, a developing Central American nation with an extensive, bicoastal exclusive economic zone (EEZ, 613,683 km²; FAO 2004), fisheries have been subject to increasing exploitation since the 1980 s by multiple sectors, including commercial tuna and sardine seiners, semi-industrial shrimp trawlers, and a diverse artisanal or small-scale sector (Alpízar 2006). Over the years, a great deal of conflict has arisen among different sectors, as well as with government agencies, in the midst of worsening scarcity. Conflicts have been especially pronounced in the more productive and heavily exploited fisheries of the Pacific region, such as the Gulf of Nicoya, a tropical estuary of great ecological and socioeconomic importance (Mack et al. 1992; Alpízar 2006).

Traditionally, the Gulf of Nicoya has been the most important region for the nation's fisheries, with reported landings that accounted for approximately $65 \%$ of total production in Costa Rica during 1994-2005 (Chacón et al. 2007). A confluence of factors including oceanic currents, nutrient upwellings, and seasonal discharge from several effluent rivers (e.g., Tárcoles River, Tempisque River) contribute to high primary productivity in the gulf, which supports a rich biodiversity of fish and benthic invertebrates (Vargas 1995). Coastal ecosystems found in the region include mangrove forests, rocky reefs, and fluvial estuaries (Salas et al. 2012). Several commercially valuable taxa are targeted in the Gulf of Nicoya, the most important of which include 
snappers (Family: Lutjanidae), croakers (corvinas, Family: Sciaenidae), snook (Centropomus spp.), seabasses (“cabrillas”; Paralabrax spp.), and prawns or shrimp (Family: Penaeidae; FAO 2004). In addition, the livelihoods of thousands of artisanal fishers from at least 16 distinct fishing communities depend directly on the abundance of fish in the Pacific region (FAO 2004). The exact number of artisanal fishers in the gulf is difficult to estimate, given the largely informal and unreported nature of artisanal fishing along the Pacific coast (Mug 2013), but it has been estimated that there are over 12,000 artisanal fishers in Costa Rica, whose landings account for approximately $73 \%$ of total capture, and a large portion of whom inhabit the coastal region surrounding the gulf (Turriago 2013).

Since the 1980s, coastal ecosystems in the Gulf of Nicoya and along the Pacific coast have been subject to abrupt and increasing pressures posed by rapid coastal development, contamination and degradation of watersheds, the increased demand for agricultural and fisheries products, and widespread illegal, unreported and unregulated (IUU) fishing (Mack et al. 1992; Turriago 2013). Development during the 1980s also facilitated the growth of a commercial industry for the harvest of shrimp using bottom trawls, a notoriously non-selective method that has had negative impacts on coastal ecosystems and fishing communities (Gallardo 2009; Alvarez and Ross 2010). Unsustainable rates of harvest have resulted in the commercial extinction of two target prawn species (Heterocarpus affinis and H. vicarious), as well as an overall increase in the number of species harvested (Wehrtmann and Nielsen-Muñoz 2009). Bycatch from trawling in the gulf has also had significant effects on the stocks of other species that are important for small-scale fisheries and food security (FAO 2004; Gallardo 2009). 
Trawling has been prohibited in the inner gulf since 1966, but it persists in adjacent areas where it greatly disturbs the seabed and threatens ecologically important taxa (e.g., sharks, sea turtles), as well as commercially valuable species that inhabit the outer gulf during their life cycle (Campos et al. 1984).

Strategies for fisheries management adopted in Costa Rica are primarily bureaucracy-based, especially in the form of weak top-down regulation (i.e., fishing licenses and localized closed seasons; Alpízar 2006) by the Costa Rican Institute of Fishing and Aquaculture (INCOPESCA), a decentralized agency of the Executive Power. A total of 20 marine protected areas (MPAs) also exist in Costa Rica, which are managed by the Ministry of Environment and Energy (MINAE), but only cover $0.9 \%$ of the nation's EEZ (Alvarado et al. 2012). National legislation and policies emphasize the importance of sustainable use of natural resources to ensure environmental protection, social sustainability, and economic growth (e.g., preamble to the Costa Rican Law of Fishing and Aquaculture; Poder Legislativo 2005). Until recently, however, no distinct mechanisms existed to recognize small-scale fishing communities' perspectives or facilitate their involvement in management.

In 2009, after urging from several communities and supporting NGOs, an Executive Decree was issued to legally recognize a type of community-based marine protected area known as Área Marina de Pesca Responsible (AMPR, or Marine Area for Responsible Fishing; Poder Ejecutivo 2009). An AMPR is a geographically delineated area of biological, fishing, or social importance, in which fishing is restricted to ensure sustainable use, management, and conservation through cooperation between government, communities, and other organizations (Poder Ejecutivo 2009). Only 
artisanal fishing methods are permitted in AMPRs (i.e., only manually operated gear and small vessels). In order to obtain the AMPR designation, a fishing community or organization must present a management plan proposal that demonstrates the social and ecological value of the marine area, outlines gear restrictions, and maps the area through a participatory zoning process. Once approved, community members must form monitoring committees by working with INCOPESCA and the national coastguard service (Servicio Nacional de Guardacostas, SNG) to ensure that AMPRs are protected from harmful fishing activities. Because it stems from the initiatives of fishing communities and their grassroots organizations, the AMPR designation was initially proposed as a form of community-based conservation, or one in which communities have sole responsibility for managing the area. However, in its current form the AMPR model represents a co-management approach, characterized by shared and collaborative governance of a protected area (Borrini-Feyerabend et al. 2013). Several AMPRs have now been established in Costa Rica, the majority of which are located in the Gulf of Nicoya region, but their implementation remains at varying degrees of progress.

Given the complexity and multiplicity of actors involved in the management of Costa Rican fisheries, a major objective of the present work is to elucidate the institutional, social, and economic context for collective action among fishers, as well as their contributions to co-management and community-based conservation in AMPRs. More specifically, the purpose of this work is to determine some of the conditions and incentives that facilitate collective action by fishing organizations, with emphasis on the role of communities and NGOs. Because of its utility for characterizing the influence of contextual factors on decision-making and social institutions, I employ the Institutional 
Analysis and Development (IAD) framework developed by Ostrom $(2005,2007)$, with special emphasis on its application for social-ecological systems and fisheries (Imperial and Yandle 2005; Ostrom 2009). An additional objective of the present work is to evaluate the design and implementation processes for two specific AMPRs - one in the locality of Tárcoles, a community on the banks of the outer gulf, and another in Chira, a large island in the inner gulf - using the design principles of enduring common-pool resource (CPR) institutions proposed by Ostrom (1990), which have been subsequently re-framed in Anderies et al. (2004) and Cox et al. (2010). The purpose of analyzing comanagement in AMPRs through Ostrom's principles is to identify both strengths and problems in design, implementation, and enforcement. To achieve the proposed research objectives, my research relies on the analysis of several types of qualitative data, including: interviews with key informants, rapid rural assessments, ethnographic observational data, and review of legal documents and gray literature. The following section provides important background information on participatory fisheries management, as well as the study sites and the methodology used in this research.

\subsection{Literature Review}

Since the 1950s, marine and coastal fisheries across the globe have been subject to a pattern of increasing industrialization and exploitation, partly as a result of technology developed during the two world wars, which led to a drastic increase in fishing capacity (FAO 2012). Other factors contributing to exploitation include rapid development and human population growth, which have increased capitalization and global demand for seafood. Additionally, Pauly et al. (2002) have pointed out the 
importance of political pressures to enhance production in newly expanded EEZs following the 1982 United Nations Convention on the Law of the Sea, wherein ratifying nations agreed to allow other parties to exploit resources they could not (Pauly et al. 2002). Over the course of a few decades, overexploitation led to the collapse of several major fisheries, the most notorious of which include the Peruvian anchoveta (Engraulis ringens) in the Eastern Tropical Pacific and the Atlantic cod (Gadus morhua) in the northwestern Atlantic (Pauly et al. 2002). Global marine landings reached a peak of 86.4 million tonnes in 1996, and have continued to decline in spite of sustained fishing effort (FAO 2012). Maintaining current consumption levels has only been possible because of efforts to manage and artificially enhance global stocks, as well as the proliferation of aquaculture (Pauly et al. 2002).

Small-scale fisheries (SSFs) support approximately $90 \%$ of all fisheries jobs worldwide, an estimate that includes both harvest and post-harvest labor (FAO and WorldFish Center 2008). In developing nations, more than half of all fisheries landings are produced by SSFs, of which 90-95\% are destined for human consumption (FAO \& WorldFish Center 2008). Direct consumption of fishery products is an important source of protein and micronutrients that may not be present in the staple diets of developing nations (Béné et al. 2007). In addition, participation in SSFs plays a significant role in ensuring food security and preventing poverty, either through direct consumption or indirectly as a source of income (Béné et al. 2007). Unfortunately, SSFs in developing nations are especially vulnerable to several factors that drive overexploitation and resource scarcity, including poor management, weak property rights and governance regimes, the neoliberalization of global and regional markets, poverty, and external 
environmental factors such as climate variability and pollution (Allison and Ellis 2001; Béné et al. 2007; Kittinger et al. 2013; Defeo et al. 2013). Additionally, the contributions of SSFs to food security and poverty alleviation in developing nations have previously been overlooked, and in some cases actively undermined, by dominant strategies for fisheries management (Béné et al. 2007).

Traditional approaches to management stem from the hegemonic intellectual thought of the mid- $20^{\text {th }}$ century, which emphasized economic markets and centralized, hierarchical government as the most favorable kinds of institutions for regulating private goods and ensuring compliance (Ostrom 2010). The conclusions of influential work by economic and political theorists like Gordon (1954) and Hardin (1968) about the economic failures and tragedies of open-access resources have been generalized and translated to the need for government regulation and privatization (Ostrom 1990). As a result, the most widely applied forms of management involve (1) top-down regulatory mechanisms aimed at reducing fishing effort and, increasingly, (2) the recognition of private property rights for participation in market-based quota systems (i.e., rights-based management, RBM; Ohashi 2010).

On one hand, centralized regulation of fishing inputs (e.g., gear and season restrictions, vessel buybacks) has largely failed to address overcapacity and, in some cases, has actually intensified competition and uncertainty among fishers (Beddington et al. 2007). Centralized governance also takes place through fishing restrictions in MPAs. As Beddington et al. (2007) point out, when the underlying problems driving overcapacity are not addressed, MPAs may simply shift overexploitation, creating patches of conservation. In addition, because they reallocate property rights over natural 
resources (e.g., access, withdrawal, exclusion), MPAs can lead to the displacement of vulnerable social groups, such as small-scale fishers and indigenous communities (Mascia and Claus 2008). On the other hand, RBM approaches (e.g., individual transferable quotas, ITQ) have been relatively more effective for achieving conservation goals, reducing uncertainty among fishers, and redistributing costs, but may similarly displace small-scale fishers who cannot afford the costs of entering quota allocation systems (Dewees 1989). Recognizing the rights of fisher groups or communities through collectively allocated community development quotas (CDQs) can potentially address some of the social impacts of RBM (McCay 2004; Ohashi 2010). In the United States, limited access privilege programs (LAPP) have been established to allocate shares of the total allowable catch (TAC) in a specific fishery to individuals, communities, and fishing organizations (e.g., associations, cooperatives; see Anderson and Holiday 2007).

Participatory approaches to fisheries management have gained increasing recognition over the last few decades as an alternative to centralized management (Ostrom 1990; Jentoft et al. 1998; Alpízar 2006; Gutiérrez et al. 2011). Participatory management refers to the direct involvement of users and other stakeholders in decisionmaking and other policy processes (e.g., implementation, enforcement), with varying degrees of decentralization. Two major types of participatory management are recognized: (1) community-based management (CBM) approaches are those in which resource users have all responsibility for managing and protecting natural resources, whereas (2) co-management may refer to a number of arrangements in which there is collaboration between resource users, governments, and possibly other stakeholders (Alpízar 2006). Wiber et al. (2004) argue for distinguishing between 'community-based 
co-management', wherein communities have primary rights and responsibilities with some remaining government involvement, and what they term 'sector-based comanagement', in which the government works with one specific fishery sector. Moreover, some co-management arrangements in developing nations have been coordinated by communities and NGOs in the absence of government participation (Evans et al. 2011). Co-management has been proposed as an integration of other commonly applied approaches - a compromise between bureaucratic regulation (e.g., top-down controls and MPAs) and community-based management, as well as one that can include market-based policies (Yandle 2003).

In recent years, the concept of adaptive co-management has received considerable attention in the academic literature (Folke et al. 2003; Carlsson and Berkes 2005; Berkes 2009; Armitage et al. 2009). The term refers to a combination of co-management and adaptive management, in which policy processes and/or outcomes are evaluated and continually improved through collaborative decision-making. Adaptive co-management stems from the acknowledgement that fisheries, like other natural resources, are part of complex and adaptive social-ecological systems (SES), wherein social institutions interact extensively and interdependently with the biophysical world (Berkes and Folke 1998). Through the lens of the SES paradigm, which combines aspects of ecological theory with the study of social systems, adaptive capacity in management can increase social-ecological resilience (Folke et al. 2003; Armitage et al. 2009)—in this context, resilience refers to the amount of disturbance or change necessary for a system to move from one relatively stable state to another (Anderies et al. 2004). For instance, Tompkins and Adger (2004) have proposed that adaptive co-management increases resilience to 
unpredictable disturbances, specifically climate change, by creating social networks that respond to changes in resource availability and by preserving ecological integrity, which may preclude resource collapse in response to disturbance. In addition, co-management is increasingly understood as a process of active problem solving in the context of dynamic SESs (Carlsson and Berkes 2005).

A number of other benefits are commonly associated with co-management, including increased efficiency, decreased transaction costs, greater success in meeting management goals, risk-sharing by actors, and ease of conflict resolution (Carlsson and Berkes 2005), as well as social learning, trust, and the growth of local institutions (Berkes 2009). In a meta-analysis of co-management arrangements for small-scale fisheries in developing nations, Evans et al. (2011) found general support for improved conditions as measured by social, governance, and environmental indicators, especially at the level of management processes. Meanwhile outcome indicators identified were generally positive but more variable, reflecting the process-oriented nature of co-management. It is important to note that no single management regime should be prescribed as ideal in all situations (Basurto and Ostrom 2009) and that user participation does not suffice to ensure good management (Carlsson and Berkes 2005).

\section{Methods}

\subsection{Theoretical Framework}

Common-pool resources (CPR) such as forests, fisheries, and irrigation water sources are characterized by limited resource flow, high subtractability (i.e., one user's appropriation of resource units reduces the amount available to other users), and a high 
cost of excluding non-group members from accessing the resource (Ostrom 1990). In fisheries, the fugitive nature of the resource exacerbates some of the problems with uncertainty of future access and exclusion. Elinor Ostrom's (1990) review of diverse case studies detailing long-lasting, self-governing institutions for the management of CPRs provides rich support for the possibility of participatory management. Findings from CPR institutions and game theory have demonstrated that resource users are capable of devising rules to address resource overexploitation and overcome the tragedy of the commons, or as it should be more aptly known, the 'tragedy of open-access' scenario, which predicts that all individuals are rational egoists and fail to act collectively without externally imposed structures for management (Basurto and Ostrom 2009).

Over the years, the work of Ostrom and colleagues in the Workshop in Political Theory and Policy Analysis at Indiana University, Bloomington, which began in 1973, has solidified into the IAD framework, a comprehensive and transdisciplinary approach to the study of institutions and collective action (Ostrom 2005, 2007). Under the IAD framework, institutions are defined as the "prescriptions that humans use to organize all forms of repetitive and structured interaction" (Ostrom 2005, 3). The core analytical unit of the IAD framework is the action arena, the setting in which actors make decisions by interacting with or within an action situation. The action situation is the set of institutions, community attributes, and other external factors that influence decisionmaking (Ostrom 2005; Figure 1). Imperial and Yandle (2005) have summarized some of the important factors to consider for the analysis of fisheries policy using the IAD framework (Table 1). In the present work, their guidelines serve as a tool for understanding contextual factors, decision-making, and overall performance with regards 
to the AMPR model as it has been instituted in Costa Rica. In addition to the former, my analysis includes consideration of socio-economic power relations and discourse as elements that influence the action arena, which Clement (2010) proposed as a means to enrich the scope of analysis using the IAD framework, particularly for the study of decentralized natural resource governance.

Figure 1. Schematic of the Institutional Analysis and Development (IAD) framework. (Source: Ostrom 2011)

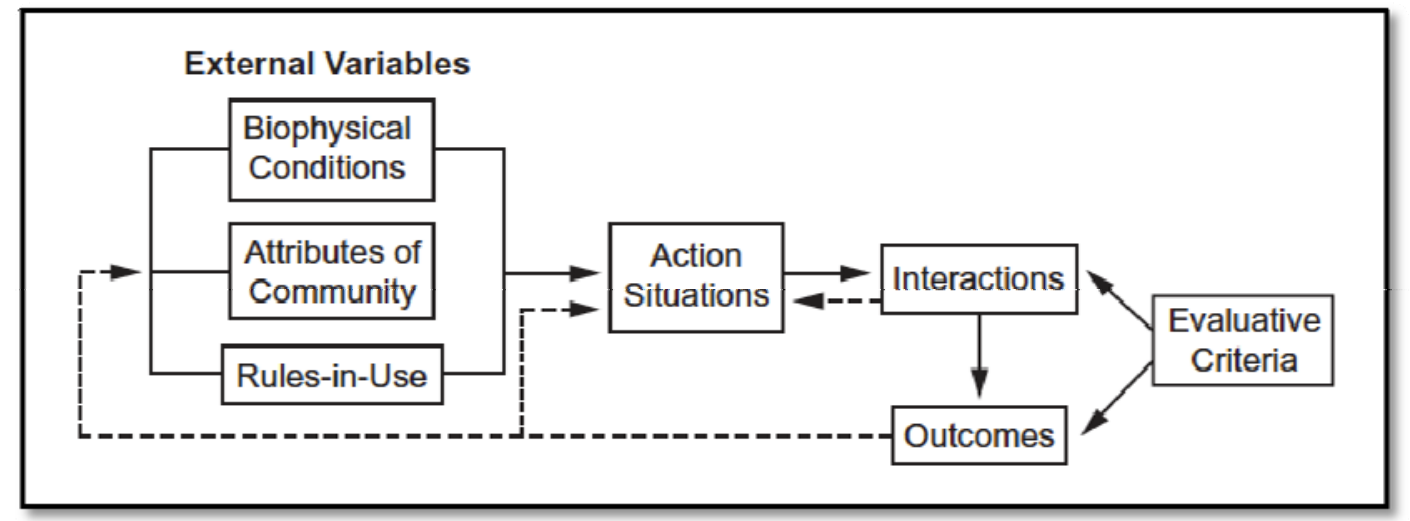

Table 1. Important factors for fisheries policy analysis using the IAD Framework. (Adapted from Imperial and Yandle, 2005).

\begin{tabular}{ll}
\hline Area of analysis & Specific factors for consideration \\
\hline \multirow{3}{*}{ Examining the Contextual Setting } & Biophysical setting \\
& $\begin{array}{l}\text { Community attributes } \\
\text { Existing institutional setting }\end{array}$ \\
& Information costs \\
Examining Transaction Costs & Strategic costs (e.g., free riding) \\
& Efficiency \\
Assessing Overall Institutional & Equity \\
Performance & Accountability \\
& Adaptability \\
& Policy outcomes \\
\hline
\end{tabular}


In her seminal book Governing the Commons, Ostrom (1990) identified eight design principles that characterize long-standing institutions for the management of CPRs (Table 2), which have since received a great deal of support in the years of ensuing research (Ostrom 2000; Cox et al. 2010). Some of the key design principles include: appropriate boundaries for the resource in question and user groups, user participation in decision-making at the collective choice level (i.e., determining rules that affect day-today operational rules), appropriate monitoring and sanctions, access to conflict resolution, and government recognition of CPR institutions. The design principles can be used as a diagnostic and predictive tool, a key to understanding the strengths and weaknesses of governance schemes. For instance, Yandle (2003) applied the design principles to evaluate the devolution of rights to stakeholder groups and the resulting comanagement regime in New Zealand. On the other hand, Anderies et al. (2004) have reframed the design principles, proposing them as baseline criteria for evaluating the robustness of SESs (i.e., robustness as a measure of sustained system performance in the face of disturbance, or a system's capacity to withstand stresses without transitioning to a different, degraded stable state). 
Table 2. Design principles for enduring CPR governance regimes. Source: Ostrom 2010.

\begin{tabular}{|c|c|}
\hline Design Principle & Description \\
\hline 1A. User Boundaries & $\begin{array}{l}\text { Clear and locally understood boundaries } \\
\text { between legitimate users and nonusers are } \\
\text { present. }\end{array}$ \\
\hline 1B. Resource Boundaries & $\begin{array}{l}\text { Clear boundaries that separate a specific } \\
\text { common-pool resource from a larger social- } \\
\text { ecological system are present. }\end{array}$ \\
\hline 2A. Congruence with Local Conditions & $\begin{array}{l}\text { Appropriation and provision rules are } \\
\text { congruent with local social and environmental } \\
\text { conditions. }\end{array}$ \\
\hline 2B. Appropriation and Provision & $\begin{array}{l}\text { Appropriation rules are congruent with } \\
\text { provision rules; the distribution of costs is } \\
\text { proportional to the distribution of benefits. }\end{array}$ \\
\hline 3. Collective Choice Arrangements & $\begin{array}{l}\text { Most individuals affected by a resource regime } \\
\text { are authorized to participate in making and } \\
\text { modifying its rules. }\end{array}$ \\
\hline 4A. Monitoring Users & $\begin{array}{l}\text { Individuals who are accountable to or are the } \\
\text { users monitor the appropriation and provision } \\
\text { levels of the users. }\end{array}$ \\
\hline 4B. Monitoring the Resource & $\begin{array}{l}\text { Individuals who are accountable to or are the } \\
\text { users monitor the condition of the resource. }\end{array}$ \\
\hline 5. Graduated Sanctions & $\begin{array}{l}\text { Sanctions for rule violations start very low but } \\
\text { become stronger if a user repeatedly violates a } \\
\text { rule. }\end{array}$ \\
\hline 6. Conflict Resolution Mechanisms & $\begin{array}{l}\text { Rapid, low cost, local arenas exist for resolving } \\
\text { conflicts among users or with officials. }\end{array}$ \\
\hline 7. Minimal Recognition of Rights & $\begin{array}{l}\text { The rights of local users to make their own } \\
\text { rules are recognized by the government. }\end{array}$ \\
\hline 8. Nested Enterprises & $\begin{array}{l}\text { When a common-pool resource is closely } \\
\text { connected to a larger social-ecological system, } \\
\text { governance activities are organized in multiple } \\
\text { nested layers. }\end{array}$ \\
\hline
\end{tabular}


In the present work, Ostrom's design principles guide the analysis of qualitative data from key informant interviews and literature review. The design principles framework will be used to identify the strengths of AMPRs as a management approach, with emphasis on two specific cases, as well as to conduct a policy gap analysis of AMPR implementation and enforcement. That is, interviews will be used to identify problems and gaps in management. The process of analyzing qualitative data and identifying themes constitutes a research process that is largely inductive and rooted in the principles of grounded theory (Glaser and Strauss 1967 in Hansen 2005), in which the formulation of theory and explanations is driven by work in the field and the analysis of qualitative data, rather than by testing hypotheses.

Key informants are individuals with extensive, specialized knowledge about social groups, local processes, policies, etc. that results from their position within a social system (Payne and Payne 2004). Key informants are valuable because they are willing and able to transmit their extensive knowledge to the researcher (Bernard 2006). Ideally, key informants should be unbiased (Tremblay 1957), but many of the actors involved in the management of natural resources have personal stakes in their work and the groups of people they represent, making it unrealistic to expect absolute objectivity from informants. Interviews with key informants have traditionally been used in ethnographic work, but can be useful for rapidly generating substantial amounts of qualitative and even quantitative data in other kinds of social research, where the focus may be narrower (Trembley 1957). Heinen (2010) has illustrated the utility of key informant interviews and other social science instruments for exploring social dimensions of conservation approaches (e.g., PAs) and identifying gaps along the policy process in the management 
of natural resources. Key informant interviews have been used for similar analyses in a number of settings, including: assessing the enforcement of regulations and management of a nature reserve in Kyrgyzstan (Ter-Ghazaryan and Heinen 2006); evaluating the regulation of the non-timber forest product (NTFP) sector in Nepal (Shrestha-Acharya and Heinen 2009); and identifying problems with the implementation of the Convention on International Trade in Endangered Species of Wild Fauna and Flora (CITES) in Nepal (Dongol and Heinen 2012).

\subsection{Study Site Description: Two AMPRs in the Gulf of Nicoya}

The first AMPR in Costa Rica was created in 2009 in Isla Chira, the largest island in the inner gulf, which is inhabited by five distinct fishing communities that rely primarily on artisanal fishing and rural tourism activities (Salas et al. 2012), as well as agriculture and salt extraction from saltpans or salinas (Babeu et al. 2013). Fishers in the

community of Palito, who predominantly fish using handlines, organized collectively as a fishing association and made the initial request to establish the AMPR to address conflict with outside fishers who exploit the area with illegal, non-selective gear, such as finemesh gillnets (Marín et al. 2012). The AMPR has since been expanded to include the waters surrounding the locality of Montero, where fishers belong to another fishing association (INCOPESCA 2012). The Palito-Montero AMPR comprises an area of approximately $6.12 \mathrm{~km}^{2}$ and protects the rocky reefs and mangroves found around the island, which serve as important breeding grounds and nurseries for pelagic species in the gulf (Salas et al. 2012; CoopeSoliDar R.L. 2013). 
Tárcoles is a village of approximately 4,300 inhabitants located on the continental coastline of the outer gulf, immediately south of the Tárcoles River delta, where conflicts between the artisanal and semi-industrial trawling sectors have been particularly pronounced (CoopeSoliDar R.L. 2010a). Approximately 50\% of the people of Tárcoles benefit directly or indirectly from fishing activities (CoopeSoliDar R.L. 2010a). Shrimp populations are especially high along the coastal zone of Tárcoles due to estuarine conditions near the mouth of the river and the role of mangroves as nurseries. The semiindustrial sector therefore concentrates its activities in this region, while artisanal fishers also harvest shrimp using gillnets with a mesh width of approximately 3 in. Artisanal fishers in Tárcoles have attributed worsening resource scarcity to the destructive practices of the trawlers that, until recently, swept the littoral zone without any restrictions (Gallardo 2009).

In 1985, a group of artisanal fishers in Tárcoles organized collectively to form a marketing cooperative, the Cooperative of Fishers of Tárcoles, or CoopeTárcoles R.L. Through the cooperative, members and non-members can sell their products at equitable prices and obtain supplies for fishing excursions (e.g., bait, ice), while members can also access subsidized fuel, store fishing gear, finance expenses, and collectively apply for fishing licenses. In 2000, CoopeTárcoles R.L. formed a relationship of associativity with CoopeSoliDar R.L., a non-governmental organization (NGO) operating under the cooperative framework, dedicated to facilitating workers' self-management and social solidarity in rural communities. It is through this partnership that community members began to take steps toward the conservation and sustainable use of the coastal-marine resource on which they depend. They voluntarily adopted a code of conduct based on the 
United Nations Food and Agriculture Organization's (FAO) guidelines for responsible fisheries (FAO 1995), which has been legally recognized as a guiding tool for management and conservation in Costa Rica (Poder Ejecutivo 1998), and also created a database to monitor landings. Additionally, CoopeTárcoles R.L. and CoopeSoliDar R.L. formed a consortium (i.e., Consorcio Por La Mar R.L.) to develop community-based tourism in Tárcoles, which provides an alternative source of income for fishers and other community members.

The AMPR of Tárcoles was officially approved in 2011 (INCOPESCA 2011) after direct negotiations between CoopeTárcoles R.L., who represented the local artisanal sector, and representatives of the semi-industrial shrimp sector. The AMPR of Tárcoles has an area of approximately $108.8 \mathrm{~km}^{2}$ (Salas et al. 2012), and has six different zones (Figure 2), each with specific gear restrictions for harvesting finfish (escama) and shrimp. For instance, in Zone 2, which extends from the mouth of the Tárcoles River to the locality of Tárcoles, only handline fishing is permitted from the coast until the $15 \mathrm{~m}$-depth bathymetry line; other gear types are permitted beyond that depth, but no fishing of any kind is permitted within a $1 \mathrm{~km}$ radius of the mouth of the river (INCOPESCA 2011). Fishers in Tárcoles employ various gear types, including gillnets with mesh sizes ranging between $3 \mathrm{in}$. and $7 \mathrm{in}$., as well as bottom-set and drifting longlines. They fish in small vessels or pangas made of fiberglass, approximately $3 \mathrm{~m}$ in length, which have outboard motors and rudimentary iceboxes for preserving product during trips. 
Figure 2. Map of the AMPR of Tárcoles, showing different zones with varying gear restrictions (Source: CoopeSoliDar R.L. 2010b).

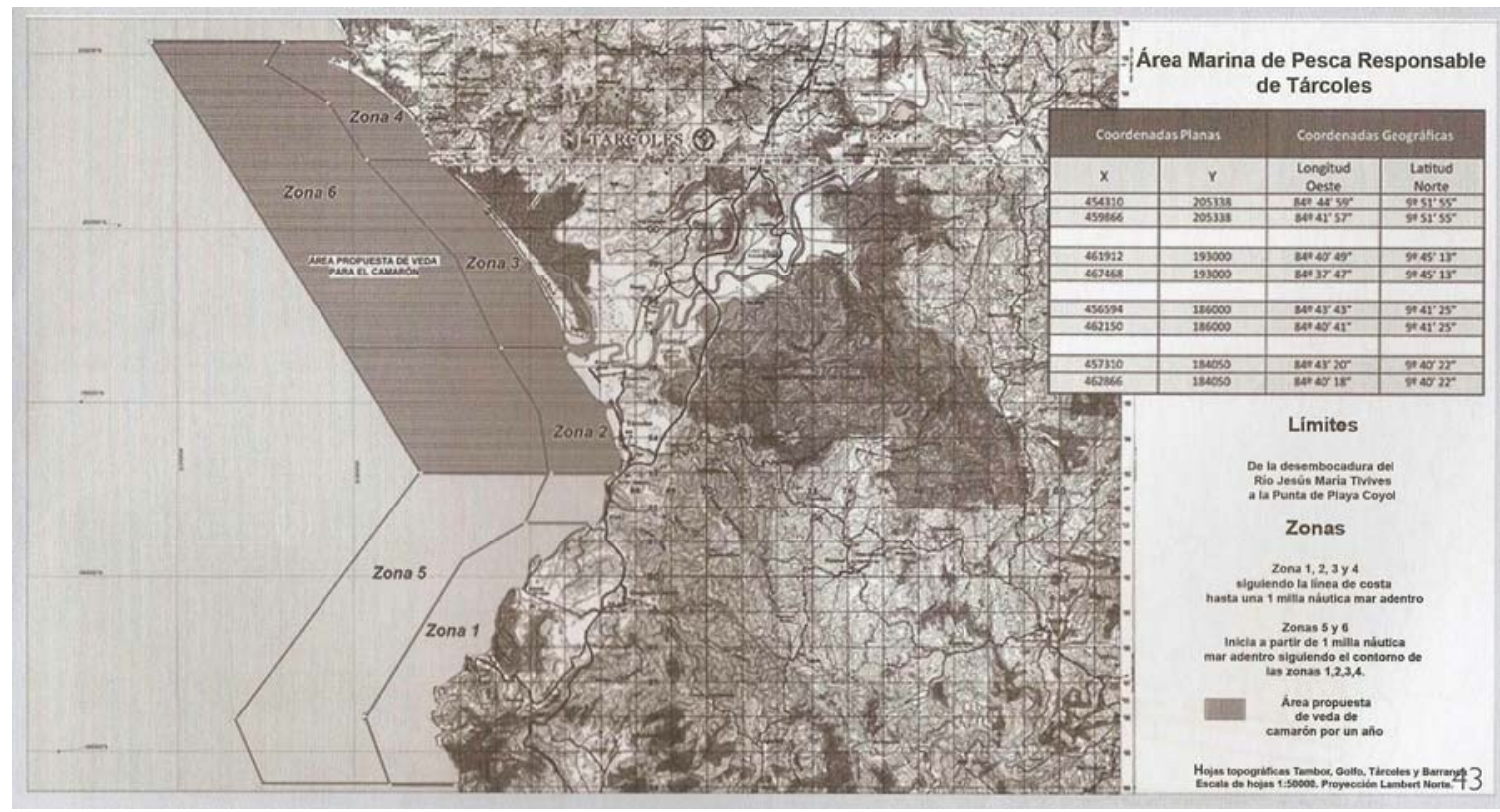

\subsection{Key Informant and Informal Interviews}

I conducted semi-structured interviews with 23 key informants who were actively involved in artisanal fishing, marine conservation, fisheries management, and AMPRs in the Gulf of Nicoya region. Interviews were carried out between July and August of 2013. Participants can be divided into two major groups: (1) local fishers and community members $(n=15)$ and (2) institutional representatives of community organizations, NGOs, or public agencies $(n=8)$. The majority of informants from Group 1 were residents of Tárcoles, except for a family of subsistence fishers living in the nearby community of Playa Azul, located between the town of Tárcoles and the mouth of the river. Group 1 was composed of 4 members of CoopeTárcoles; 6 independent fishers, all of whom also sold product to the cooperative; 3 ex-members of the cooperative who fished for several 
years but are currently engaged in other occupations; one post-harvest and clerical worker for CoopeTárcoles R.L.; and one local innkeeper with a long history of fishing in Tárcoles, currently also involved in community-based tourism with Consorcio PorLaMar R.L. On the other hand, Group 2 consisted of two representatives of community organizations in Tárcoles; three members of NGOs working with fishing communities in the Tárcoles and Chira AMPRs (i.e., CoopeSoliDar R.L. and Fundación MarViva respectively); two members of government agencies involved in fisheries regulation and conservation (i.e., INCOPESCA and the SNG); and finally, one researcher and professor at the Universidad Nacional de Costa Rica (UNA), Puntarenas, who has been involved in developing baseline ecological research for AMPRs in the gulf.

Sampling for participants was non-random and purposive (Bernard 2006), as informants were specifically chosen because of their roles in communities and organizations. In some cases, the selection of informants was participant-driven, or influenced by referral from other informants and inquiries within the community. Prior to being interviewed, participants were informed about the general purpose of this research and assured that participation would be voluntary and, in the case of Group 1, anonymous. Representatives of CoopeTárcoles R.L. and CoopeSoliDar R.L. were opposed to the anonymity of their statements and those of cooperative members, citing the problematic erasure of actors' personhood and humanity in scientific research. Because informants in Group 2 represent specific organizations and were interviewed in their corresponding workplaces, their identities are not anonymous. A list of institutional informants can be found in Appendix 1. However, in order to protect other participants 
from any unintended consequences that may result from their responses about other actors, the identities of informants in Group 1 will remain anonymous.

A great deal of baseline socio-economic information has been collected for the communities of Tárcoles (CoopeSoliDar R.L. 2006, 2009, 2010a) and Isla Chira (Babeu et al. 2012), which heavily informs the current analysis. In my interviews with fishers and community members in Tárcoles, questions focused instead on determining participants' relationship to fishing, fishery regulation, involvement in AMPRs, and their perceptions of the strengths and weaknesses of management policies and institutions for collective action. Specific interview questions varied for each informant, as the interview process led to differing subjects of discussion. For Group 1, interviews began with questions about participants' life history in relation to fishing, their current occupation, and their perception of the current state of fishing as an economic activity. Then, fishers in Group 1 were asked about the economic activities they adopted, both generally and in response to scarcity, in order to assess the degree of flexibility in their livelihood strategies. Finally, informants in Group 1 were asked about the benefits of belonging to the local cooperative (CoopeTárcoles R.L.), as opposed to working independently; the problems they observed in the cooperative and regulation in general; and their opinion on the importance of marine conservation.

Similarly, interview questions varied in specificity between informants in Group 2, but were designed to understand the role of individuals and their corresponding organizations in fisheries management, regulation, marine conservation, and their work with communities. Interviews began with questions about informants' work and area of expertise, as well as their involvement with communities and specific AMPRs. Then, 
informants were asked about their opinion on current management in AMPRs, the strengths of the approach, and the obstacles or problems they perceived. Informants were prompted to expand their explanations of conflicts, problems, and difficulties in the management of AMPRs and fisheries in general. In the case of representatives of government agencies especially, questions also sought to clarify informants' specific

roles in management, their perceptions of other actors, and problems they identified with implementation and enforcement of national policies.

In addition to interviews with key informants, I carried out a number of informal interviews with fishers and community members in the localities of Tárcoles, Isla Chira, Puntarenas, and Costa de Pájaros to supplement my knowledge of community dynamics and conduct a rapid rural appraisal (RRA; Chambers 1994) of fishers' attitudes, observations, and their perceptions of problems in fisheries management. Participants for informal interviews were selected using purposive, participant-driven sampling in Tárcoles - i.e., obtaining information from community members with whom I became familiar, as well as others to whom they referred me. Sampling was less purposive in the other locations. Interviews were carried out along major areas where fishers gathered (e.g., the port and fish market of Puntarenas; the port of entry and hostels in Isla Chira).

\subsection{Qualitative Data Analysis}

Interviews were recorded using a digital audio recording device, translated from Spanish to English, and transcribed into separate documents. The translated transcripts were subsequently coded using the computer-assisted qualitative data analysis software Atlas.ti (version 7.0). After a preliminary coding of transcripts using broad themes (e.g., 
equity, conflict, accountability), a structured coding system was created to facilitate the identification of emergent themes and subthemes, as well as to address specific research questions. Findings from coded interviews are supplemented with review of a number of documents produced by NGOs working with the communities of interest, government reports, and other relevant literature.

\section{Results and Discussion}

\subsection{Socio-economic and Institutional Context for Collective Action and AMPRs}

The economic activities of greatest importance in Costa Rica are tourism, for which the nation is widely known, and the production of agricultural and industrial goods for exportation. Following a dire economic crisis in the late 1970s, the latter industries experienced rapid recovery and growth as a result of structural adjustment economic policies adopted in the 1980s, which were fostered through loans from the World Bank (Vega 1996). Structural adjustment was characterized by increased market liberalization, privatization of industries formerly regulated by government, and the development of powerful neo-exportation sectors for trade with the U.S. and Europe (Vega 1996). Between 1976 and 1983, the Costa Rican government implemented a similar development model, promoted by the Inter-American Development Bank (IDB), which aimed to increase productivity in the nation's fisheries and improve the socioeconomic status of fishers (Ovares 1989). Approximately \$20 million were allocated for investments, which focused mainly on the development of infrastructure (e.g., port facilities, vessel construction) and the promotion of fishing cooperatives in the artisanal sector (Breton 1991). However, according to Breton (1991), these initiatives constituted a 
resounding failure: the budget was neither fully nor efficiently utilized, fewer vessels were constructed than initially planned, and a cooperative created for managing development activities dissolved after declaring bankruptcy. Additionally, in the absence of capacity building to accompany technological improvements, these development policies exacerbated debts and losses in the artisanal sector (Breton 1991).

The cooperative model has been promoted in Costa Rica and readily accepted as beneficial for stimulating economic growth and development in rural communities-not only through the aforementioned structural adjustment initiative, which provided economic incentives and capitalization, but more broadly through a long history of national policies. The 1973 Law of Cooperative Associations (Law N ${ }^{\circ} 4179$ ) defines cooperatives as voluntary associations of persons, with full juridical identity, in which individuals organize democratically to promote economic and social improvement, and wherein the goal is to provide a service as opposed to generating profit. In addition to establishing guidelines and creating the Institute for the Promotion of Cooperatives (INFOCOOP), Law $\mathrm{N}^{\mathrm{o}} 4179$ also creates a series of economic incentives for cooperatives, primarily in the form of tax exemptions. Over time, cooperativism has become an integral part of the political and economic discourse in Costa Rica. For instance, in 1980, Law $\mathrm{N}^{\circ} 6437$ made it obligatory for all educational institutions in the country to include cooperativism in their curricula.

However, at least in its initial application among artisanal fishers, the cooperative model has yielded some negative results, which can be attributed to disparities between cooperative ideology and the social realities of fishing communities. Ovares (1989) examined the failures of two fishery cooperatives in the Gulf of Nicoya created during 
the structural adjustment period, illustrating some of the problems. The first was a marketing and harvest cooperative that was artificially formed by recruiting fishers from the entire region, many of whom were not full-time fishers but were provided with a processing facility, vessels, and gear. The other was a production cooperative, composed of members of an existing cooperative, who traditionally worked in salt production and harvested mollusks but had little experience in fishery production. In both cases, members had little to no experience in the management or administration of cooperatives. In the latter, members did not feel a sense of ownership over the cooperative and became passive members or neglected the organization. Both eventually went bankrupt and dissolved. According to Breton (1991), because these initial attempts at cooperativism in SSFs were pushed by international organizations and local bureaucracies, they were not representative of fishers' values or voices. They did not address the basic needs of fishers, nor did they bridge educational gaps (Ovares 1989). As Bené et al. (2007) have pointed out, the policies most frequently promoted for fishery development in developing nations - exemplified by these attempts in Costa Rica — have focused on production and rent-maximization, instead of adequately enhancing the potential for SSFs to relieve poverty and sustain local economies.

Although some cooperatives exist, fishers in Costa Rica organize more commonly into fishing associations. Associations differ juridically from cooperatives in that members are not required to provide an initial financial contribution to a common fund, and associations serve to benefit each member of the society, rather than to fulfill a common economic or social goal ( Law N $^{0} 218$, Law of Associations). Fishing associations are also not generally geared towards production or marketing activities. 
Instead, they may specialize in communal development or solidarity, much like cultural associations (Law $\mathrm{N}^{0} 218$ ). For the purpose of understanding community-based conservation and co-management in Tárcoles and Chira, the distinction between these organization types is tenuous. Both involve democratic decision-making through general assemblies, where members are elected to fulfill administrative and other duties. Moreover, according to a recent characterization of institutional and civil actors, fishing organizations in the Gulf of Nicoya tend to focus on facilitating paperwork and licenses, as opposed to capacity building and community development (Marín Cabrera 2012). However, in the cases of Tárcoles and Palito, both types of fishing organizations play significant roles in community development, capacity building, and the promotion of alternative economic activities. Nonetheless, the differences between the two cases are rooted in economic factors - namely, differential access to local and regional markets. In the following subsections, I explore some of the incentives for and benefits of sustained collective action in Tárcoles and Chira, as well as some of the factors that have facilitated the creation of AMPRs.

\subsection{Incentives for Collective Action in Tárcoles}

CoopeTárcoles R.L. is the only marketing and production cooperative of smallscale fishers remaining in Costa Rica (Marín Cabrera 2012). Some cooperatives exist in the commercial sector (e.g., among shrimp and tuna producers), while others focus on the provision of fishing supplies. There are currently 40 members in CoopeTárcoles R.L., five of which are women. Some members fill elected positions in the cooperative's specialized councils: an Administrative Council, which oversees administrative and 
operational activities (e.g., reports, sales, expenses); a Monitoring Council that monitors and supervises all activities, including those of the Administrative Council, to ensure proper functioning; and finally, a Committee on Social Welfare, which addresses social and communal development activities (e.g., beautification of communal spaces; D. Chacón, interview, 2013). Major decisions and elections are made during an annual general assembly of all members, and positions are elected by majority vote. There are also approximately 10 employees working in the administrative office, the processing facility, and the storefront. Unlike other fishing cooperatives in Costa Rica, CoopeTárcoles R.L. has survived since its inception in 1985, overcoming bouts of internal conflict and financial turmoil. According to the responses of several informants, the cooperative faced significant administrative issues during its first fifteen years, including: debt and financial deficits, which one fisher attributed to excessive leniency in financing fishers' expenses; a related problem of alcohol abuse and short-sighted handling of earnings among fishers; embezzlement by administrators, who were hired individuals from outside the community; and internal theft of product by employees in the cooperative's storefront.

Findings from interviews with fishers and other community members in Tárcoles suggest that incentives for collective action among fishers are overwhelmingly tied to economic factors - as much for the formation and maintenance of the cooperative as for requesting the recognition of the AMPR. Several respondents, including the president of the cooperative, cited problems with intermediaries as a major impetus for cooperativism. Distributors would commonly cheat locals, buying product from fishers at significantly lower prices than was reasonable in relation to market prices, which shifted profit away 
from the community. Additionally, the fishers accrued debts with suppliers whenever fishing trips were not successful. The cooperative became an instrument for guaranteeing fair prices, selling fishery products collectively through a common storefront, and collectively financing expenses for supplies, therefore bypassing the need for intermediaries and external suppliers. Organizing under the cooperative framework was also considered beneficial by founding members because of tax incentives and ease of access to fishery development programs.

Moreover, the labor and profit distribution model employed in CoopeTárcoles R.L. is characterized by financial equity, a characteristic cited by seven informants as a strength of the cooperative. Once landings from a fishing trip are turned in to the cooperative for appraisal and expenses are subtracted, profits are divided equally among three parties: the vessel owner (a cooperative member), the captain, and the peón or worker aboard the vessel. In cases when the vessel owner is also the captain, he or she receives two thirds of the profit. On the other hand, according to several fishers, workers aboard commercial vessels receive significantly smaller shares. One fisher recalled being offered $10 \%$ of profits as a worker aboard a shrimp trawler, which he qualified as unreasonable considering the intensity of labor and time spent at sea.

When asked about their perceptions of the importance of conservation in the area of Tárcoles, all fishers recognized it as important if not essential, but their responses reflected an emphasis on the economic benefits of conservation for fishing activities. Three participants expressed a view that their support of conservation was contingent upon its coexistence with sustained fishing. Fishers are not in favor of protectionist conservation that excludes the small-scale sector from marine resources. Moreover, nine 
fishers expressed that removing the shrimp trawlers from the area of Tárcoles is critical for conservation of the resource. The fact that economic interests figure prominently among fishers' reasons for acting collectively and requesting the AMPR is not necessarily negative. Rather, it may stem from the socio-economic instability that disproportionately affects the sector. In these communities, collective action for the preservation of rural livelihoods is a matter of survival in the face of rapid coastal development, which is taking place to meet demand from tourism throughout the region, and the rapid degradation of coastal resources (CoopeSoliDar R.L. 2010a).

In their responses, fishers also claimed that factors such as trust, unity, similarity, and familiarity among members have contributed to the endurance of the cooperative over the years. This finding is seemingly consistent with Ostrom's (1990) assertion that small, homogenous groups are more likely to overcome the dilemmas of collective action and organize for the management of CPRs. Community members in Tárcoles have similar educational levels, cultural and religious practices, and a shared history of place, albeit one that is relatively brief. Generally speaking, fisheries in Costa Rica remained largely undeveloped until the 1980s (Breton 1991). Findings from interviews indicate that fishing is indeed a novel economic activity in Tárcoles. All fishers interviewed had started fishing within the last two generations. Eight participants had learned to fish as a livelihood-sustaining activity from their fathers or uncles, who were the first generation of fishers in Tárcoles, while five had become the first fishers in their families. All began fishing at an early age, usually in their early to mid-teens, as workers aboard vessels or under the direction of elders. The village of Tárcoles itself has only existed since the 1950s, and a majority of its inhabitants are migrants from other regions of the country 
who traveled to the area in search of economic opportunities (CoopeSoliDar R.L. 2010a). All community members interviewed reported that their families previously depended on agriculture and livestock, activities in which few of them continue to engage. Informants' responses suggest that the high abundance of fish previously found in Tárcoles—and accordingly the ease of capturing valuable fish — created an incentive for people to shift away from traditional livelihood strategies. With time, fishing became central to the cultural identity and livelihood of people in Tárcoles, where approximately $90 \%$ of its inhabitants were once fishers (CoopeSoliDar R.L. 2010a). Recent attempts at community development and political advocacy in partnership with CoopeSoliDar R.L., which emphasize the potential for community-based conservation, explicitly aim to rescue the community's cultural identity from disappearing under the current development model.

\subsubsection{The role of an external organization: CoopeSoliDar R.L.}

After comprehensive consideration of all interviews and documents, it has become evident that the association between CoopeTárcoles R.L. and CoopeSoliDar R.L. has been a significant tool for expanding available forms of capital and facilitating sustained collective action in Tárcoles. The relationship has directly influenced community involvement in political self-advocacy, resource management, and community-based conservation through the AMPR. CoopeSoliDar R.L. have been involved with CoopeTárcoles R.L. through a process of continual informed consent, wherein cooperative members agree and decide upon the role of the external organization - which differs radically from the approach of environmental and 
international NGOs, one that often imposes frameworks for development and is characterized by short-term projects with temporary funding (V. Solís, interview, 2013).

By facilitating training and capacity building for community members, the relationship between the two cooperatives has increased the available human capital (i.e., skills and knowledge) of the community. Several efforts have been made to bridge educational gaps in the community, including workshops and the development of appropriate educational materials to inform community members about conservation, the law, and other topics. After 2000, when the cooperative became involved with CoopeSoliDar R.L., members began to address some administrative issues and reform the bylaws of the organization in order to include a vision of sustainability (D. Chacón, interview, 2013). Cooperative members realized that they could manage their own internal affairs without the need to hire external managers, and administrative positions within the cooperative are currently filled by local people who have been trained for management (D. Chacón, interview, 2013). In the same vein, the two organizations are actively involved in participatory research, wherein community members collect information about socio-economic indicators, as well as fishing effort and resource abundance. The research priorities are determined through consensus; the results are analyzed and synthesized by members of CoopeSoliDar R.L., and then employed by both organizations to make future decisions. Research efforts include a systematized database of landings.

Moreover, through the jointly formed Consorcio PorLaMar R.L., the two organizations have been working to develop a model for rural community-based tourism, in which tourists and educational organizations can travel to Tárcoles, experience the 
community, and learn about artisanal fishing (J. Naranjo, interview, 2013). The consortium has increased the available human capital, developing fishers and other community members' skills for giving guided tours; it has strengthened social ties and increased leadership among cooperative members, who are actively involved in maintaining the consortium through elected councils and assemblies; and it has provided an avenue for increasing financial capital outside of fishing activities. In addition, the work of CoopeSoliDar R.L. has allowed the community to access funding from other organizations, obtained through work with larger organizations (e.g., Conservation International) and individual donors — an important source of financial capital. For instance, a large icemaker located in the cooperative storefront was acquired using donations and allows the cooperative to produce ice for members' fishing trips, as well as to sell ice to independent fishers. In addition, administrative improvements and selfmanagement have ostensibly improved the management of the cooperative's communal fund, made up of each member's contribution to the association.

Furthermore, because the members of CoopeSoliDar R.L. are experts from various fields (e.g., anthropology, biology, law) and have a variety of skills to offer the community, their relationship with the cooperative has also facilitated the formation of linkages between the community and other levels of governance. In a process that originated in the community, the two organizations requested that INCOPESCA recognize a community-based marine area in which the cooperative could regulate permitted gear, prior to the legislation enabling AMPRs. Costa Rica does not recognize collective property rights over natural resources, although it does recognize the sparse indigenous reserves that remain in the nation (Madrigal and Solís Rivera 2012), but their 
urging influenced the development of AMPRs as a model for recognizing fishers' rights - a process in which CoopeSoliDar R.L. and CoopeTárcoles R.L. were heavily involved with INCOPESCA (V. Solís, interview, 2013). As a result of community involvement, not only from Tárcoles but also other communities, the AMPR model is one that reflects the political influence of small-scale fishers as a user group.

The role of CoopeSoliDar R.L. in helping small-scale fishers create cross-scale linkages and voice their considerations in a larger political arena can be described in two similar ways. Adger (2003) makes the distinction between bonding social capital, which refers to the relationships and social bonds found in communities, and networking social capital, which relates to relationships with external actors or groups. Findings from this research suggest that CoopeSoliDar R.L. have acted as a catalyst to strengthen and increase the existing social capital in CoopeTárcoles R.L. On one hand, improved leadership and cohesion from within the community has enhanced existing social bonds and made CoopeTárcoles R.L. a more valuable organization for the community. Then, by promoting horizontal linkages with other fishing communities in the region and vertical linkages with government agencies and larger international forums (e.g., the United Nations Equator Initiative), the relationship with CoopeSoliDar R.L. has increased the stock of networking social capital available to the cooperative of Tárcoles.

Birner and Wittmer (2003) have described certain processes whereby groups of people are able to transform social capital into political capital; by political capital they refer to the "resources used by an actor to influence policy formation processes and realize outcomes that serve the actor's perceived interests" (Birner and Wittmer 2003, 298). In requesting the creation of an AMPR and participating in the design of the policy, 
the fishers of Tárcoles have had a direct impact on the kind of legislation available for the co-management of fisheries in Costa Rica. The support of CoopeSoliDar R.L. has been essential in this process, especially for filling gaps in information and providing technical assistance - to achieve recognition of an AMPR, fishing organizations must gather substantial information about the community and resource and propose an appropriate management plan. Beyond the creation of the AMPR, the fishers of CoopeTárcoles R.L. have been able to negotiate other aspects of management in the regional political arena. As a result of the initial negotiations that determined gear restrictions for the AMPR of Tárcoles, a complete ban on all fishing within the area was established in 2012 for the duration of a year, for both shrimp trawlers and artisanal fishers. This arrangement was not perceived as fair by fishers in Tárcoles, who proceeded to collect information on resource abundance and the impacts of fishing gear during that first year (D. Chacón, interview, 2013). A year later, the fishers were able to demonstrate the recovery of the resource and succeeded in eliciting a new decree, whereby trawlers are permanently banned and artisanal fishers are allowed to fish in the area with some restrictions. The renegotiation of fishing regulation in the AMPR demonstrates how, by conducting their own research, the cooperative of Tárcoles was able to influence decision-making and shift policy outcomes towards their perceived model of equity and sustainability.

\subsubsection{Additional benefits of the cooperative}

There are several ways in which the cooperative produces benefits that extend beyond its members and propagate throughout the community. Cooperative members have access to commercialization and equitable prices for landings, but the majority of 
independent fishers in Tárcoles also sell their fish to the cooperative. A family of subsistence fishers interviewed in Playa Azul reported that access to commercialization through the cooperative has been important for their survival. The family lives in a small brick house with rudimentary infrastructure, and since they lack freezer or storage capabilities, any fish they catch must be sold within 24 hours to local businesses or to the cooperative.

According to several informants, the cooperative is beneficial because it generates jobs for community members. A number of people are involved in pre- and post-harvest labor, which entails baiting longline hooks and untangling fishing nets. The majority of pre- and post-harvest workers are women, who are known as lujadoras, and in some cases also their children. According to one lujadora, working for the cooperative is a good source of informal labor with flexible hours, which supplements her other activities. She also works as a clerical worker for the cooperative. It is worth noting that fishing activities are more commonly undertaken by men in the community, though perhaps unsurprisingly, given the physical nature of the labor and the salience of traditional, essentialist gender roles. Meanwhile, the majority of informal labor in Tárcoles is carried out by women who cook, wash clothes, rent rooms, etc. in order to supplement family incomes. The same applies in the case of lujadoras, whose informal work is strenuous but make significantly less money than fishers. However, according to a recent synthesis of social data from the community (CoopeSoliDar R.L. 2010a), women's increasing involvement in various economic activities has promoted increased autonomy and agency in the community. Additionally, the informal nature of labor might grant them the 
flexibility to care for their children and other family members, as pointed out by one community member interviewed.

Biological monitoring undertaken by CoopeTárcoles has demonstrated an increase in prawn populations within the AMPR after the fishery closed for a year. Additionally, community members have observed an increase in the abundance and variety of mollusk species along the littoral zone, which are locally harvested and play a role in food security. These findings illustrate how management through the AMPR has benefited local ecological conditions. Finally, the community-based tourism initiative undertaken through Consorcio PorLaMar R.L. is providing an alternative source of income for some of the fishers, who give guided tours of fishing activities, but also for some of the women who collect mollusks in the vicinity and participate as tour guides. The tourism initiative was cited by three of the fishers as a valuable alternative, a way to make use of fishing vessels to supplement their incomes that does not require fishing. Others in town also benefit from the tourism, especially women who rent rooms as innkeepers and restaurant owners.

\subsubsection{Livelihood strategies}

One of the objectives of this study was to assess the degree of flexibility and diversity in the livelihood strategies of fishers in Tárcoles. Although seemingly ancillary to the other research questions, examining livelihoods - the assets, activities, and access to which directly affect how people make a living — is important for understanding the vulnerability and adaptability of small-scale fishers to changes in resource availability (Allison and Ellis 2001). According to Allison and Ellis (2001), vulnerability is 
determined not only by external factors that increase risk - in this case, the overexploitation and contamination of the gulf's marine resources, as well as rapid coastal development threatening fishers' rights to coastal land (CoopeSoliDar R.L. 2009) - but also by the ability of fishers to adapt to risks, which is often operationalized in terms of resilience or robustness. They demonstrate how, contrary to simplistic policies that frame it as static, the fishing sector is dynamic in composition and fishers respond to different drivers (e.g., demand, resource flow) in a variety of ways.

The fishers of Tárcoles exhibit limited livelihood flexibility from one standpoint. For a majority of fishers in the Gulf of Nicoya, fishing is intricately tied up with community identity; they are interested in continuing to fish and are less willing to drastically shift to alternative economic activities than fishers in other regions of the country (Marín Cabrera 2012). In Tárcoles, where fishing has been a primary economic activity and remains important for community members, established fishers are persistent and reluctant to seek livelihoods outside the fishing sector. Four participants claimed that, when faced with resource scarcity, they continue to fish week after week regardless of accruing debt to suppliers or the cooperative. Formal and informal interviews indicate that fisherfolk value occupational independence - i.e., not being subordinate to a boss or manager and having flexible schedules. However, their persistence in the face of scarcity cannot be entirely attributed to unwillingness. There are few economic alternatives in Tárcoles, and even less in nearby Playa Azul, which is further from the highway that connects coastal towns. Aside from continuing to fish when landings are scant, it is possible for fishers to work as farmhands in nearby agricultural operations or in construction, both of which usually require them to travel outside of town. According to 
community members' responses in Tárcoles, these are not regarded as sources of stable employment but can help supplement income seasonally. One fisher interviewed in Playa Azul travels for additional labor during the less productive dry season (December-April). Another alternative is to work in some segment of the tourism sector, which is also mediated by distance and, more importantly, education. The majority of people in Tárcoles only achieve a grade school education, and few are fluent in foreign languages. Nonetheless, CoopeSoliDar R.L. (2010a) have noted that transportation from Tárcoles to other coastal cities has improved in recent years with the construction of the main highway, which is contributing to community development in terms of access to jobs and education.

Of the informants interviewed, three ex-fishers and one cooperative member in Group 1 have transitioned into or oscillated between fishing and local tourism. Two of them work as guides or captains in a local boat tour of the Tárcoles River, showing tourists the high densities of American crocodiles and birds along its banks; one of them also owns a fishing vessel and is associated to the cooperative, but allows others to fish in it while he works in tourism and collects a portion of the profit. Another is the owner of one of three crocodile tour companies in Tárcoles. The last one is a founding member of the cooperative, who left during the years of financial conflict, and has since worked as a security guard in nearby hotels and for a crocodile tour company. One of the fishers interviewed emphasized the hardships of fishing, and expressed a desire for his children to gain an education rather than become fishers. His response illustrates how attitudes seem to be shifting in the community at large, which may be at the brink of a change in livelihood strategies. A survey carried out by CoopeTárcoles R.L. and CoopeSoliDar 
R.L. indicated that a large proportion of youth in Tárcoles perceive obtaining an education and entering other labor markets as the best way to improve the future of the community (CoopeSoliDar R.L. 2010a).

Although opportunities are limited for the current generation, the fishers of Tárcoles exhibit a high degree of intra-sector flexibility, as indicated by their diversification of fishing strategies. Allison and Ellis (2001) noted that livelihoods are complex, and can change seasonally or cyclically in response to resource availability. Fishers in Tárcoles use traditional knowledge of lunar cycles to predict high populations of shrimp, and have great knowledge of specific fishing grounds. Moreover, several respondents claimed that acquiring different fishing skills improved their ability to make a living. Fishers in Tárcoles employ a variety of gear for different target groups: gillnets between 5" and 7" in mesh width are used to harvest commercially valuable species (e.g., spotted rose snapper, Lutjanus guttatus; snook, Centropumus spp.); gillnets with finer mesh-sizes (3-3.5”) are used to harvest shrimp; bottom-set longlines are used for capturing demersal fish species (e.g., corvinas, Family: Sciaenidae; groupers, Epinephelinae spp.), while surface longlines specifically target mahi-mahi or dorados (Coryphaena hippurus), which are more common during certain times of the year; and finally, some fishers practice free-diving for lobsters, especially in Zone 1 (see Figure 2), although it is no longer permitted as per the AMPR management plan. In addition to gear diversity, fishers depend heavily on mobility as a means to increase their catches - this is a troubling point, given that some fishers now travel as far as the southern border of the country and even Panama to find fish. Of course, access to diverse fishing strategies is inflected by class. Some fishers, especially those I interviewed in Playa Azul, have no 
access to vessels with powerful motors or different types of gear, which makes them especially to vulnerable to scarcity and changes in regulation. More careful study would be beneficial for determining the adaptability of fishers' livelihoods in this entire region.

\subsection{Collective action and external organizations in the Isla Chira AMPR}

Because the majority of my fieldwork was conducted in Tárcoles, the case of the AMPR in Isla Chira is presented more briefly here to provide perspective on a different case, one in which grassroots fishing organizations have also worked with en external organization for the management of the marine area. Two very different communities are part of the Palito-Montero AMPR in Isla Chira. In Palito, the Association of Handline Fishers of Palito (ASOPECUPACHI) is composed of entirely of handline fishers, as their name suggests. They have been committed to sustainability and responsible fishing since 1995, when they requested that fishing gear be restricted in the area currently protected as the AMPR - protection was granted by INCOPESCA well before the enabling legislation (Salas et al. 2012). The fishers of ASOPECUPACHI have since maintained a monitoring program to prevent the use of gillnets in the area (CoopeSoliDar R.L. 2013). The fishers of Palito have received greater attention and support as a result of their initiatives, and were responsible for establishing the AMPR that has now covers both communities (Babeu et al. 2013). On the other hand, the Association of Mixed Fishers of Montero (ASOMM) only recently began shifting towards more sustainable practices. Their request to protect their portion of the marine area was approved in 2012 as an extension of the Palito AMPR. Many fishers in Montero still use fine-mesh gillnets, which have low selectivity, to capture shrimp outside of the AMPR (Babeu et al. 2013). Members of 
ASOPECUPACHI oppose the use of gillnets, which they perceive as harmful for the resource (CoopeSoliDar R.L. 2013), but some non-members from Palito and the majority in Montero still utilize them because shrimp is a more valuable product than fish captured using handlines (Babeu et al. 2013). Nonetheless, fishers in Montero recognize the necessity and benefits of the AMPR, and contribute to monitoring and enforcing the management plan (CoopeSoliDar R.L. 2013).

The fishers in Palito do not have their own receiver or storefront, although they are in the process of creating one (Babeu et al. 2013). Fishers here are also isolated from the mainland, which decreases the potential for commercialization. The majority of them sell fish to the same intermediary, a local with whom they have accumulated varying and inconsistently recorded debt over the years (Babeu et al. 2013). On the other hand, fishers in Montero sell their product to fish markets for local consumption on the island (Babeu et al. 2013). In a recent socioeconomic study of the two fishing communities, Babeu et al. (2013) found that the majority of families interviewed live below the poverty line and approximately $50 \%$ of them relied on additional sources of income to supplement their livelihoods, since fishing was not sufficient. In addition, many fishers in the island are in debt with the social security office, which affects the availability of basic health care for the inhabitants (J. Cole, interview, 2013). Members of ASOPECUPACHI are actively involved in communal development and seek capacity-building courses or workshops to improve their skills, to a greater degree than non-members in Palito and fishers in ASOMM (Babeu et al. 2013; CoopeSoliDar R.L. 2013). In Palito, the members of ASOPECUPACHI have also developed an aquaculture project for farming oysters, in which several members and non-members are now involved (Babeu et al. 2013). The 
oyster project and the various courses taken by community members have provided a means to increase available human and financial capital, as well as to diversify livelihood strategies - these are efforts that stem from within community organizations.

Fundación MarViva is an environmental NGO that has traditionally worked in marine conservation in Colombia and Panamá, and recently began working in Costa Rica. The organization acquires funding from several sources, including other NGOs, government, trusts, grants, and donations. Their objectives have centered on creating an ecological corridor in the Eastern Tropical Pacific, focusing on regions of biological importance that have received less attention than the Galápagos Islands off the coast of Ecuador (J. Cole, interview, 2013). In Costa Rica, the work of MarViva was initially protectionist. They established agreements with INCOPESCA, MINAE, and the SNG for jointly patrolling MPAs. As a result, they were not initially well received by communities in the southern estuary of Golfo Dulce, an area with the largest AMPR in the country and where most fishers have now transitioned into tourism-related activities (J. Cole, interview, 2013). Over time, MarViva have shifted their focus, recognizing the importance of communities and socioeconomic factors on the success of marine conservation strategies. They have worked extensively with communities of fishers in Golfo Dulce, where fishing associations had formed a federation of fishers to represent collective interests (i.e., Federación Nacional de Pescadores Artesanales y Afines, FENOPEA). According to Jorge Cole of MarViva (interview, 2013), the work has produced tangible results with regards to implementation of the AMPR and improving socioeconomic conditions through partnerships with a government aid program (i.e. Instituto Mixto de Ayuda Social, IMAS). 
The relationship between fishers in Palito-Montero and MarViva was established more recently. MarViva has helped the fishers establish connections with Product C, a different intermediary that trades in sustainable seafood, as well as to begin a process that will facilitate eco-labeling of fishery products (J. Cole, interview, 2013). In combination, increasing the communities' access to commercialization and obtaining the recognition of sustainable fishing through certification have the potential to improve fishers' socioeconomic status. Helping to increase the value of fishery products through a specialty market that rewards fishers for responsible fishing has greater promise for sustainability than increasing the productivity of SSFs, as policies have aimed in the past. Certification may also shift economic incentives that affect fishing behavior. Instead of fishing for shrimp because of its higher value, fishers might begin to use handlines exclusively in response to improved prices. However, the economic benefits of these strategies have not been significant yet, and there is some indication that fishers are discouraged from participating in the associations and the protection of the AMPRs (Babeu et al. 2013; J. Cole, interview, 2013). In addition to helping with commercialization, MarViva has produced some research detailing the socioeconomic status of community members (i.e., Babeu et al. 2013); they are currently working in participatory research with fishers to determine the impact of various fishing gears; they have created opportunities for capacity building on the island; and are also working on creating connections between community members and the IMAS program (E. Ross, interview, 2013; J. Cole, interview, 2013).

A few key similarities and differences between the situation in Chira and Tárcoles are worth noting here. In both cases, external organizations have been instrumental for 
increasing the networking social capital of fishing organizations, especially in terms of vertical linkages to improve marketing and to increase political influence in Chira and Tárcoles respectively. In both cases, collective action is threatened by illegal fishing and gaps in enforcement, as the following section will address in greater detail. However, the economic benefits of the cooperative in Tárcoles are significantly clearer and acknowledged by community members than those of organizations in Chira. The difference in benefits seems largely a result of access to regional markets, an aspect that has been more directly addressed in Tárcoles through the marketing cooperative. As conditions continue to improve in Palito, given that the community is poised to create its own storefront, it will be useful to determine whether benefits increase for members of ASOPECUPACHI or whether insularity will continue to play a role in access to commercialization.

Regarding the participation of external organizations, the relationship between MarViva and the fishers in Chira is characterized by a greater degree of independence than that observed between CoopeSoliDar R.L. and CoopeTárcoles R.L., which exhibits a greater degree interdependence and collaboration. While some participatory research is taking place between MarViva and fishers in Chira to determine the impacts of fishing gear in the area (E. Ross, interview, 2013), the research process that has taken place in Tárcoles has resulted in significantly greater involvement by community members. More specifically, while fishers in Tárcoles define the parameters of necessary research and are actively involved in the collection of both socioeconomic and biological data, a project undertaken by MarViva to collect baseline socioeconomic information was carried out by university students from the United States (i.e. Babeu et al. 2013). On one hand, the latter 
approach might generate information more rapidly and require less effort than training community members on adequate research practices, but it is possible that the research produces fewer long-term benefits for the community (i.e., in terms of human and social capital). Nonetheless, both organizations are making important contributions to these communities, helping them bridge gaps in knowledge and create connections that will be instrumental for their improvement and development.

\subsection{Policy gap analysis: Ostrom's design principles}

The first of Ostrom's design principles pertains to boundaries in two senses: specifically, (1A) appropriate boundaries for the resource in question and (1B) boundaries for user groups allowed to exercise certain property rights over the resource (Table 1; Cox et al. 2010). According to Ostrom (1990), meeting these criteria enables users to resolve the issue of exclusivity; i.e., being able to exclude non-members from accessing and appropriating the resource. At least by the parameters that initially defined it, the AMPR of Tárcoles does not neatly fit the first design principle. The area is explicitly designed not to exclude users, but to modify appropriation rules based on ecological considerations for each of its six zones; and user groups in the area are diverse, including largely unlicensed subsistence fishers, more advanced small-scale fishers (i.e., those with highly mobile vessels and specialized gear), and shrimp trawlers. Additionally, because of the fugitive nature of various target species, it is difficult to define the resource stocks and to ensure their availability to some users. Fishers have also noted that INCOPESCA has taken a long time to place buoys to demarcate the AMPR, the absence of which makes monitoring and enforcement difficult. 
During the first year, all fishing was prohibited from the coastline to the $15 \mathrm{~m}-$ depth bathymetry line, which resulted in improved shrimp stocks that subsequently spilled over to the area where shrimp trawlers could harvest them. Artisanal fishers could not harvest shrimp at greater depths using their gear, nor could they fish within the AMPR at all, an arrangement they did not consider fair. In 2013, the fishers of CoopeTárcoles R.L. have made and supported claims about the recovery of the resource following the exclusion of trawlers, as well as for the potential of sustainable harvest within the area by artisanal fishers. INCOPESCA has reformed the AMPR agreement, which now includes a permanent ban of trawlers in the littoral zone up to the $15 \mathrm{~m}$-depth line. This new arrangement does facilitate exclusivity for artisanal fishers, which they feel addresses the issue of spillover and creates an incentive for continued protection of the area.

Similarly, in Chira there is a clearly defined boundary for the AMPR, in which fishing gear is restricted but not access. The Palito-Montero AMPR is a much smaller area with fewer users and it is relatively easier to determine whether users are violating the established appropriation rules, especially in Palito where fishers have defended the area since 1995. In Palito, there are buoys to delimit the AMPR, but incentives for users to patrol the area have weakened in light of questionable benefits (J. Cole, interview, 2013). As in Tárcoles, fishers in Palito have expressed that protecting the AMPR does not preclude overexploitation or the use of harmful fishing gear elsewhere in the gulf (Babeu et al. 2013), making it difficult to exclude others from the stocks improved as a result of the communities' conservation efforts. In Montero, fishers have also decried the lack of 
buoys and appropriate environmental investigation by government agencies (CoopeSoliDar R.L. 2013).

As several critiques of this first principle have pointed out, boundaries do not necessarily have to be clear-cut for appropriate management, and valuing clear boundaries may reflect a desire for analytical ease (Cox et al. 2010). In the cases of the aforementioned AMPRs, there are boundaries established by geographic coordinates, but the resource is not thereby confined, nor are boundaries between social groups easily distinguished. While acknowledging the benefits of AMPRs for small-scale fishers who have gained recognition, one institutional informant pointed to the need for all fishing in Costa Rica to be 'responsible' in order to prevent patchwork conservation (E. Ross, interview, 2013). However, as it stands now, fishers have repeatedly noted the inefficiencies of government agencies with respect to placing buoys, conducting appropriate investigation, and communicating clearly with users (CoopeSoliDar R.L. 2013), all of which threaten the legitimacy of AMPRs.

Regarding the second principle, Cox et al. (2010) determined two separate criteria for evaluation: first, $(2 \mathrm{~A})$ congruence between rules for management and local conditions, which may include ecological and social considerations; and (2B) agreement between provision rules and appropriation rules, where provision refers to the investment made by a group of people for maintaining and augmenting the resource, and appropriation refers to harvest or extraction. In Tárcoles, gear restrictions are generally concordant with ecological conditions. Gillnet mesh-size and length limitations, as well as regulations for hook type (i.e., using less harmful circular hooks instead of J-hooks) and length of longlines aim to increase selectivity and prevent the harvest of juveniles, 
which would have detrimental effects on fish stocks. However, gillnets have low selectivity and can result in incidental catch of sharks and cetaceans, while longlines have moderate selectivity but can also pose problems with shark bycatch (Ross Salazar 2014). Additionally, the impacts of trawling immediately outside of the bathymetry line are certainly not in agreement with local ecological conditions. Therefore, more detailed investigation is necessary to determine the impact of appropriation rules in Tárcoles.

An additional finding emerged from interviews with institutional informants, which is not specific to the management of AMPRs but indicates a discrepancy between appropriation rules in the gulf and ecological conditions. Since 1985, a series of seasonal bans on all fishing activity in the gulf have been established in order to protect peaks of reproduction for various species. During the bans, artisanal fishers are compensated for their lost income. However, only licensed fishers are compensated and the livelihoods of countless unlicensed, subsistence fishers are not recognized. Moreover, INCOPESCA has recently acknowledged that the bans have not achieved any recovery objectives, in part due to non-compliance and lack of control (Fundación MarViva 2013). According to one informant, the commission in charge of planning closed seasons is composed of commercial fishing interests, and the bans do not coincide with actual reproductive peaks, which may further explain the policy's failure. Overrepresentation of fishing interests in determining closed-seasons exemplifies capture of the policy process by commercial interests, an issue that must be addressed for ensuring sustainability.

As far as social conditions, rules are largely fitting with traditional fishing methods in the sense that fishers are familiar with permitted gear, but restrictions on gillnet use and mesh size have not been well-received by some artisanal fishers. In Playa 
Azul, for instance, illegal gillnets are commonly placed across the Tárcoles River, which seriously threatens species that migrate to the estuary for spawning. Only two families of subsistence fishers live in Playa Azul, one of which refused to be interviewed and is presumed to be responsible for these illegal nets. The family I interviewed reported that restrictions on mesh-size make it difficult for fishers like them to make a living, because they lack mobility to open ocean where the fish are larger. Reconciling regulations with local conditions is difficult in this case, but may require education and capacity building to ensure adequate livelihoods for rural fishers. In Chira, conditions are especially fitting of ecological and social conditions in Palito, as fishers have been employing low-impact handlines for a long time. Handline fishing is highly selective and fishers can easily prevent incidental capture of ecologically significant species or individuals below the size minimum (Ross Salazar 2014). Fishers in Montero practice gillnetting to a greater extent than fishers in Palito, but they do so outside the relatively small AMPR and have expressed no problems with the established appropriation rules.

In both Tárcoles and Chira, ensuring that the costs of investing in the maintenance of the resource are equitably distributed among users and that benefits from improved management are proportional to investment presents a greater challenge. In Tárcoles, the renegotiation of fishing restrictions in the AMPR that resulted in the exclusion of trawlers has been a victory in this regard — it has addressed the inequality in benefits fishers perceived when all fishing was banned. The problem of freeriding persists, for instance, when fishers who use illegal gear or who are not invested in monitoring the AMPR benefit from augmented stocks. However, interviews suggest that individuals with greater involvement in the cooperative and fishery development activities receive greater benefits 
than those who are uninvolved. Additionally, the vision of CoopeTárcoles R.L. has never been to exclude community members, but to create a shift in practices in the entire community (D. Chacón, interview, 2013). Meanwhile, in Chira, the perception of benefits greatly influences involvement in monitoring for the AMPR and fishing associations (Babeu et al. 2013). Freeriding is much more prevalent, given the high incidence of illegal gillnets, and fishers do not yet see economic benefits that are substantial enough to merit sustained involvement (J. Cole, interview, 2013).

The third design principle entails that actors who are subject to operational rules (i.e., rules for resource extraction) also have the ability to participate at the collectivechoice level (i.e., in changing operational rules). In both Chira and Tárcoles, users have worked in a participatory manner with INCOPESCA to determine gear restrictions and zoning. Participation of user groups in a common setting to determine operational rules is a key strength of the AMPR approach, as it facilitates self-determination and representation in an arena from which small-scale fishers are otherwise routinely excluded. However, because operational rules are determined through collaboration between different users, government agencies, and NGOs, the ability to modify operational rules is not as flexible as in some CBM arrangements where users have greater control. Additionally, in Chira information about the resource is not always readily available for making operational changes, nor is it as easy to shift operational strategies. Fishers in Tárcoles have worked to establish systematized knowledge of landings. They have greater flexibility in terms of mobility, are not constrained by restrictions outside of the AMPR, and can therefore make more strategic decisions about fishing effort. 
The fourth principle relates to two specific characteristics of monitoring, both of which emphasize the accountability or membership of a monitor to the user group: (4A) a monitor for appropriation and provision levels, and (4B) a monitor of the resource's condition (Cox et al. 2010). Fishing organizations that request AMPRs are ostensibly involved in overseeing the use of the resource through monitoring committees, which also include members of INCOPESCA and the SNG. Fishers can notify the SNG, the agency charged with patrolling all territorial waters, about illegal activities taking place. However, fishers have expressed that monitoring committees fail to meet and work successfully, and that patrolling measures are currently insufficient (CoopeSoliDar R.L. 2013). The SNG's functions are severely undermined by budgetary and personnel constraints. The agency counts with an annual budget of approximately 7,000 million colones ( $\sim \$ 12 \mathrm{M}$ USD) and 500 employees; they only manage to secure coverage of $40 \%$ of coastlines, $25 \%$ of the territorial waters, and $0.05 \%$ of the EEZ, and must prioritize the prevention of drug trafficking (C. Castro Moralers, interview, 2013).

In Tárcoles, several fishers reported that the SNG patrollers disproportionately stop artisanal fishers to ask them for licenses and inspect gear than they do larger vessels. Informal interview respondents in Tárcoles and Chira also claimed that SNG officers were confiscating illegal gear and re-selling it to fishers at unofficial auctions- - this issue merits a rigorous investigation to facilitate accountability. However, collaboration between fishers and the SNG officers has arguably improved in Tárcoles, with some jointly attended training workshops (V. Solís, interview, 2013). In Palito especially, fishers have also taken monitoring into their own hands through the vigilance activities initiated in 1995. As mentioned previously, their monitoring system is costly (e.g., in 
terms of time, effort, fuel) and fishers are discouraged to continue without adequate support. In Montero, monitoring is similarly carried out by users, but they are in need of a vessel for monitoring (CoopeSoliDar R.L. 2013).

Finally, because all the former constitute monitoring of resource users, it is important to note that few parties are conducting research on ecological conditions in the Gulf of Nicoya. Fishers in Tárcoles have collected information on the resource, but none of it is publicly available. Meanwhile, INCOPESCA and the UNA are also conducting some baseline ecological research to aid in the creation of new AMPRs (A. Rojas, interview, 2013), but research tends to focus on commercially valuable species and there has not been a broader assessment of resources in the gulf (Mug 2013). Several other communities in the process of implementing AMPRs have reported major gaps in investigation (CoopeSoliDar R.L. 2013).

The fifth design principle stems from Ostrom's (1990) observation that a number of enduring CPR institutions have mechanisms for graduated sanctions-i.e., sanctions that increase in severity in proportion to violations. Graduated sanctions are available within fishing organizations. For instance, in CoopeTárcoles R.L., the assembly can suspend a member's privileges (e.g., fuel, financing) for committing a violation to the cooperative norms, such as selling fish in another port (D. Chacón, interview, 2013). If violations recur or become more serious, the assembly has the power to permanently bar the member. On the other hand, sanctions for violating appropriation rules in the AMPR are mediated by the nature of co-management with the SNG. Formerly, only confiscation was available as a sanction for illegal gear, but a reform of the Law of Fishing and Aquaculture (Ley $\mathrm{N}^{\mathrm{o}}$ 8436; Poder Legislativo 2005) incorporates graduated pecuniary 
sanctions for certain illegal fishing activities. However, because inconsistent patrolling results in little certainty of sanctions for violations, the current system does not adequately deter illegal fishing. Finally, some unofficial enforcement also takes place. In Palito, fishers have fiercely defended the area from gillnetters by cutting or removing their nets (J. Cole, interview, 2013). In Tárcoles, when finding an illegal net in the river, one fisher expressed a reluctance to remove or cut it in order to avoid conflict with other fishers, which had occurred in the past. In both AMPRs, there are serious gaps in monitoring and enforcement that the communities cannot fill without support.

The sixth design principle requires that users and officials have access to rapid, low-cost mechanisms for conflict resolution, within user groups and also between users and officials (Ostrom 1990). Conflict resolution is low-cost and easily accessible within community organizations, such as CoopeTárcoles R.L. According to one informant, fishers in the cooperative easily and vocally express discontent with other members' actions and bring problems to light during meetings and assemblies, in spite of their otherwise reserved temperament. However, conflict resolution is not readily available between users and officials of government agencies. Three informants have expressed that some officials of INCOPESCA have been uncooperative and unwilling to take required actions. For instance, after making a request for a hearing with the Board of Directors of INCOPESCA five different times and being ignored, one community organization resorted to the National Ombudsman's Office for achieving compliancethis is an instance in which conflict resolution had a substantial transaction cost. Similarly, the NGOs MarViva and PRETOMA (Programa Restauración de Tortugas Marinas) have resorted to filing lawsuits against INCOPESCA for noncompliance in its 
responsibilities (PRETOMA 2013; Solano 2014). Addressing the accountability of government agencies, particularly INCOPESCA, remains a significant obstacle for management.

Finally, the seventh and eighth principles described by Ostrom (1990) are both related to cross-scale linkages between appropriators and other levels of governance. Principle 7 states that appropriators' rights to establish their own rules are not undermined by governments, whereas Principle 8 , which applies to larger systems, indicates that management activities (e.g., appropriation, provisioning, conflict resolution, enforcement) should be nested within stratified levels of governance. The management of an AMPR, in this case, is connected to fisheries regulation in the entire gulf, as well as at the constitutional level. As a policy, the AMPR model represents a shift in the direction of the seventh and eighth principles, by creating the space for small-scale fishers to propose gear restrictions and management plans that are subsequently supported by the state. By virtue of the co-management framework, all aspects of design, implementation, and regulation hypothetically involve collaboration between users and various government agencies, which validate and support users' rules. In reality, there are some major gaps in these functions, as well as in the efficiency of government agencies.

The majority of informants interviewed reported that INCOPESCA is not an adequately functioning government agency; it favors the interests of its more powerful constituents in the commercial sector; conflicts of interest undermine the agency's regulation, especially within its Board of Directors; and its employees are largely uncooperative and unresponsive to fishers. As mentioned previously, NGOs have resorted to suing INCOPESCA and its former president for non-compliance and 
withholding information. Additionally, despite a substantial lack of information about the state of marine resources in the Gulf of Nicoya, the agency continues to issue licenses to fishers (Mug 2013) — most recently, it also renewed the licenses of several shrimp trawlers, going against a constitutional ruling (Solano 2014).

Lack of funding seriously impairs the organization's ability to fulfill its numerous functions. The agency only counts with approximately 140 employees throughout Costa Rica (B. Marín, interview, 2013). INCOPESCA was established in 1994 as a decentralized entity of the Executive Branch, but gaps in funding and effective enforcement have plagued fisheries management in Costa Rica for decades. When management was carried out under a division of the Ministry of Agriculture and Livestock (MAG), only 3-4\% of the ministry's total funding was available for fisheries (Mack et al. 1992). Breton (1991) also pointed to the lack of funding for the development of SSFs and similarly suggested that funding was preferentially allocated to the growth of the agricultural sector. A significant change is necessary in the agency's structure, available funding, and oversight, as some analysts have already suggested (e.g., Mug 2013). It is necessary to strengthen and streamline linkages between users and government organizations, improve collaboration, and make funding available to programs such as AMPRs. The role of NGOs has been crucial for beginning that process, but a great deal of work remains in the coming years.

\subsubsection{Additional problems identified}

Fishery subsidies: Of all the informants interviewed for this work, only one pointed to the impact of harmful subsidies on fisheries management in Costa Rica. In the 
year 2000, approximately $70 \%$ of fisheries subsidies in Costa Rica ( $\$ 32 \mathrm{M}$ USD) were the kinds generally classified as harmful (Sumaila and Pauly 2006). That is, they create incentives for increased exploitation and maintain high fishing effort even while fishing is not profitable (e.g., fuel subsidies, tax exemptions, fishery development). All licensed fishers in Costa Rica are eligible for exonerated fuel (Poder Legislativo 2005), making it the most common kind of subsidy. Fluctuations in fuel prices increase the vulnerability of SSFs and livelihoods (FAO and World Fish Center 2008), which suggests that fuel subsidies may be alleviating some of the uncertainty among artisanal fishers. However, in the absence of stronger strategies for management and social development, fuel subsidies simply act as an incentive to continue fishing even though stocks are overexploited.

Climate change adaptation: Only one informant in all interviews mentioned the issue of climate change, one that is expected to have serious repercussions for small-scale fishers and coastal cities in the coming decades. Aside from the threat of sea level rise to fishers' towns, coastal fisheries are especially vulnerable to decreases in productivity and the effects of climate variability (e.g., increased El Niño-Southern Oscillation events). The specific impacts of climate change on fisheries are expected to vary, but will likely depend on the degree of involvement and measures adopted for adaptation (Merino et al. 2009). Therefore, adaptation to changes in the coming years needs to become a central conversation for coastal communities, and may have to be facilitated in the settings considered for this study. 


\section{Conclusions}

From the current work, as well as from the many efforts of communities and NGOs explored in this thesis, it is evident that there is potential for communities to become protagonists of marine conservation in Costa Rica. Some have been working towards sustainability for a long time, and others have recently embarked in the processes necessary for change. Both kinds of communities will require support to bridge gaps in knowledge and leadership, as well as to address socioeconomic problems (e.g., poverty, access to alternative livelihood strategies) in the coming years. The government of Costa Rica has fortunately recognized the importance of involving small-scale fishers in management processes, most clearly evidenced by the recognition of AMPRs and the design of two new MPA categories that permit sustainable harvest in MPAs (Solís Rivera et al. 2012). The efforts of fishing communities, grassroots organizations, and NGOs have been crucial for the development of these new strategies. Nonetheless, as the findings from my thesis indicate, there are several areas of management that require improvement, not only in the development of the AMPR model, but also generally in fisheries regulation.

Prior to the development of the AMPR model and new MPA categories, Alpízar (2006) proposed that INCOPESCA and MINAE work as one agency in order to increase and optimize the use of available funding, as well as to unify fisheries and marine conservation goals, noting that some of their activities may not be complementary. Alpízar (2006) also called for greater participation from diverse stakeholders, and that MPAs should be more inclusive of the artisanal fishing sector. Management is shifting towards the latter, but the Costa Rican government must seriously consider the need for 
managing fisheries under the same considerations adopted for other natural resources and biodiversity. Other analysts have also recommended changing the structure of INCOPESCA to remove its overly influential Board of Directors and increase representation of small-scale fishing interests (e.g., Mug 2013). Decreasing the influence of commercial interests is critical for managing these exploited fisheries in the future, as regulation is currently under capture from these economically powerful interests. Moreover, increasing the budget and training available for fisheries regulation is necessary for improving monitoring and enforcement in these areas.

Regarding the adaptability of small-scale fishers in the gulf, it may be beneficial to encourage different fishing associations to form larger organizations, as has been the case with FENOPEA in the southern region, through which fishers act collectively on a regional scale and increase their political influence. In addition, increasing the frequency of meetings for monitoring committees and their ability to alter operational rules in AMPRs may increase the adaptability of fishing organizations to changes in resource flow, although it may increase transaction costs of management. With adequate capacity building, it might be possible to devolve the rights over operational rules even further so that communities can shift fishing practices. However, methods for assessing stocks must be implemented urgently to guide management, and there must be some mechanism for accountability to prevent ecological harm from unsustainable gear types.

As Erick Ross from MarViva suggested (interview, 2013), it would also be beneficial to promote the integration of AMPRs and promote responsible fishing in the entire gulf. The various AMPRs in the Gulf of Nicoya-Palito-Montero, Isla Caballo, Tárcoles, and now Isla Venado, as well as others that are still emerging - currently form 
small patches of conservation where only relatively sustainable fishing methods are in use, but unless the entire region undergoes a reform in terms of permitted gear and fishing intensity, the effects on restoring biodiversity and stocks will be limited. Fortunately, the ability of INCOPESCA to issue permits for shrimp trawlers has been suspended indefinitely. The trawlers, which in actuality comprise a small portion of fishers in the nation (only 73 vessels as of 2008; Alvarez and Ross 2010), have responded with protests and demonstrations in order to reinstitute their rights to harvest in this way. A new bill is being pushed to reinstitute licenses for 'sustainable' trawling (PRETOMA 2014), which illustrates the persistence of these commercial interests, and must be opposed. Communities of artisanal fishers and NGOs are working tenaciously towards greater social and ecological sustainability, but a significant shift will be necessary in the political realm in order to effect the changes necessary to protect these fisheries for future generations. 


\section{LEGAL ANALYSIS:}

Applying the Institutional Grammar Tool to Understand Fishery Regulation in Costa Rica

\section{Introduction}

The importance of artisanal or small-scale fisheries (SSF) for food security, sustainable livelihoods, and alleviating conditions of poverty in developing nations has gained increasing attention in the academic literature (Allison and Ellis 2001; Defeo et al. 2013; Kitinger et al. 2013) and in the work of international nongovernmental organizations (NGOs; e.g., Bené et al. 2007; FAO and WorldFish Center 2008). More than half of fisheries landings in developing nations are generated by small-scale fishers, 90-95\% of which are directly consumed by people (FAO \& World Fish Center 2008). Small-scale fisheries also provide approximately $90 \%$ of all fisheries jobs worldwide (Kittinger et al. 2013). Some characteristics of SSFs in developing nations include: multiple target species and gear types, vulnerability to climatic variability, weak regulation, and thus susceptibility to overcapacity and high rates of illegal, unreported, and unregulated (IUU) fishing (FAO \& World Fish Center 2008; Kittinger et al. 2013). In the Gulf of Nicoya, a rich tropical estuary on the Pacific coast of Costa Rica, the artisanal sector captured approximately 9,714 metric tons/year from 1994-2005, which comprised $65 \%$ of the nation's total landings (Chacón et al. 2007). The artisanal sector in the Gulf of Nicoya is made up of several thousand fishers who directly rely on capture for subsistence through direct consumption or sale in local and regional markets - the exact number is difficult to estimate, but there are approximately 12,000 artisanal fishers in all of Costa Rica, a large portion of which live in the gulf region 
(Turriago 2013). Recent findings support the conclusion that SSFs continue to be critical for social sustainability and local economies in Costa Rica, as well as throughout Central America (Solís Rivera et al. 2012; Turriago 2013).

During the 1970s, Costa Rica developed an extensive national park and protected area (PA) system, comprised primarily of terrestrial PAs with some adjoined marine portions. Currently, there are 20 marine protected areas (MPAs) in Costa Rica, which cover only approximately $17.5 \%$ of the territorial waters and $0.9 \%$ of the nation's vast exclusive economic zone (EEZ; Alvarado et al. 2012). Communities dependent on fishing grounds in these areas were never consulted or included in the decision making processes that resulted in MPA designation and associated fishing restrictions (Solano 2005). Protected areas are arguably necessary for managing ecologically important zones, but non-inclusive planning undermines communities' traditional rights of access and tenure over natural resources. Some of the unintended social impacts generally associated with the global increase in national parks and other PAs, which include displacement and economic losses to livelihoods, have been thoroughly reviewed in West and Brockington (2006). However, the specific impacts stemming from the management of MPAs have received considerably less attention (Solís Rivera et al. 2012) or have been the subject of studies limited by sample size and heterogeneity (e.g., Mascia et al. 2010).

In Costa Rica, some mechanisms have been developed for the inclusion and participation of local communities in the management of MPAs, as well as new forms of marine governance in Costa Rica. Most notably, a legal framework exists that recognizes fishing organizations or communities' requests to establish marine conservation areas in which fishing is restricted to manual, small-scale methods, known as Marine Areas for 
Responsible Fishing (AMPR; Poder Ejecutivo 2009). Gear restrictions in AMPRs are determined using the United Nations Food and Agriculture Organization's (FAO) code of conduct for responsible fisheries (FAO 1995), which has been legally recognized as an important tool for management in Costa Rica (Executive Decree $\mathrm{N}^{0} .27919,1998$ ). Fishing organizations and other stakeholders determine the extent of AMPRs through a participatory zoning process. Once determined and approved, the areas are implemented and enforced using a co-management approach in which communities collaborate with government agencies, namely the Costa Rican Institute of Fisheries and Aquaculture (INCOPESCA) and the national coastguard service (SNG), by forming monitoring committees.

In spite of recent moves toward inclusion, however, case studies from the region suggest there may be conflicts of interest in the management of MPAs, which preferentially benefits profitable sectors (e.g., touristic recreational, industrial), and that there are a number of underlying social problems left to address (e.g., poverty, education), all of which preclude fully participatory management in MPAs and AMPRs (Solís Rivera et al. 2012). Additionally, communities generally do not feel included or represented in decision-making for the management of MPAs in Costa Rica (Solís Rivera et al. 2012). Findings from my fieldwork and interviews with community members of several communities in the Gulf of Nicoya suggest that social inequalities affect fisheries and environmental regulations. More specifically, several participants and community members have expressed that rules and enforcement practices affect the artisanal sector disproportionately and that large-scale interests are favored. 
Current environmental policy and legislation in Costa Rica tend to emphasize the need for sustainable use of natural resources by multiple users, citing their importance for the development of communities dependent on them, as well as for economic growth and environmental protection (e.g., Poder Legislativo 2005). However, the aforementioned findings may reflect incongruences between the stated objectives of legislation and the nature of the rules being prescribed, as well as their enforcement. Grounded in the social construction framework of analysis, Schneider and Ingram (1993) suggest that social constructions of populations targeted by policy may result in the inequities that pervade regulatory action (e.g., in agricultural policies of the United States). By social construction, the authors refer to the "cultural characterizations or popular images of the persons or groups whose behavior and well-being are affected by public policy" (Schneider and Ingram 1993, 334). The reported complaints with respect to fishery policies in Costa Rica — specifically, the lack of representation and unequal prescription of rules to the detriment of small-scale stakeholders - may stem from constructed perceptions of fishers, whether rooted in reality or not. Several informants interviewed during July and August of 2013 suggested that fishers are perceived as lazy and wasteful, in spite of their work being physically and emotionally demanding. More generally, the high incidence of poverty among small-scale fishers throughout the world has been repeatedly framed as the consequence of their own inability to manage fisheries, thus justifying the need for top-down regulation (Béné 2003). According to Schneider and Ingram (1993), the social constructions of target populations can affect the distribution of costs and benefits that result from policy actions. Social constructs are influenced by the existing ideology and values about specific groups' roles in society, which are set in 
specific 'geographies of discourse'-i.e., the ways in which ideas are produced, disseminated, and consumed, which are shaped by the specific socio-economic context and power relations at play in different settings (Dixon and Hapke 2003).

The objective of the current paper is to conduct a systematic analysis of relevant policies currently being implemented in Costa Rica in order identify potential biases at the level of legislation and officially adopted practices. Because of its comprehensiveness and documented suitability for the study of institutions governing common-pool resources (CPR), the present study employs elements of the Institutional Analysis and Development (IAD) framework (Ostrom 2005, 2007) to understand and describe the context of policies. More specifically, I apply the institutional grammar developed by Crawford and Ostrom (1995) to analyze legal documents related to the management of fisheries and AMPRs in Costa Rica. The following section provides some important background on the analytical framework and its application.

\subsection{The Institutional Grammar Tool}

Crawford and Ostrom (1995) originally proposed the institutional grammar as a general framework for the linguistic analysis of institutional statements, which they define as the specific prescriptions actors use to structure institutions. Institutions, in turn, are the set of rules that arise from repeated and structured interaction between actors (Ostrom, 2005, 3). Basurto et al. (2010) emphasize the distinction between institutions as and institutional statements - the former is a broader concept that includes stated rules and unwritten "rules-in-use," whereas the latter refers to statements that are linguistic in nature, are explicitly stated or written, and can thus be analyzed as separate units of 
observation. Basurto et al. (2010) and Siddiki et al. (2011) have refined the analytical framework into an institutional grammar tool (ITG), providing more specific instructions for applying it, as well as contextual factors to consider.

The syntax of the revised ITG contains six linguistic components that may be identified in each institutional statement, represented by the acronym ABDICO. A summary of syntax elements and examples can be found in Table 3. The attribute (A) refers to the actor, either an individual or a group, to whom the institutional statement applies or who must carry out the action prescribed. The attribute may be clearly defined or described in the statement, but it may also be implicit (Basurto et al. 2010). The attribute takes a prescribed action upon the object (B), which may be animate or inanimate. The object was not part of the original institutional grammar, but has been adopted because it has been found to increase intercoder reliability (e.g., among members of a research team) and reduce ambiguity in coding (Siddiki et al. 2010). The deontic (D) is the prescriptive operator of the statement, which determines whether an action is allowed (Permitted), required (Obliged), or prohibited (Forbidden)—e.g., must, must not, may, should, etc. (Crawford and Ostrom 2005). The deontic is normally explicit, but Basurto et al. (2010) have suggested that it can also be implicit (e.g., if already stated in a previous statement). The aim (I) of an institutional statement is the action itself, that which is taken by the attribute. The condition (C) refers to any qualifiers of the aim, including when, where, or how the action is to take place. If the condition is not explicitly stated, then the default condition can be understood as "at all times" (Siddiki et al. 2011, 85). Finally, the or else (O) component is the sanction or punitive action associated with violating the prescription of the institutional statement. 
Table 3. Definitions and examples of IGT syntax elements.

\begin{tabular}{|c|c|c|}
\hline $\begin{array}{l}\text { ADICO } \\
\text { Component }\end{array}$ & Definition & Coding Examples \\
\hline Attribute & $\begin{array}{l}\text { Agents charged with performing a } \\
\text { particular action* }\end{array}$ & $\begin{array}{l}\text { Fishers } \\
\text { Fishing organization } \\
\text { INCOPESCA }\end{array}$ \\
\hline oBject & $\begin{array}{l}\text { Animate or inanimate part of the } \\
\text { statement that is the receiver of an } \\
\text { action* }\end{array}$ & $\begin{array}{l}\text { AMPR management plan } \\
\text { Fishing license }\end{array}$ \\
\hline Deontic & $\begin{array}{l}\text { Prescriptive operator that specifies } \\
\text { whether an action is required, } \\
\text { permitted, or prohibited* }\end{array}$ & $\begin{array}{l}\text { Must/must not } \\
\text { May/may not }\end{array}$ \\
\hline $\mathrm{a} \mathbf{I m}$ & Action* & $\begin{array}{l}\text { Communicate } \\
\text { Obtain } \\
\text { Practice fishing }\end{array}$ \\
\hline Condition & $\begin{array}{l}\text { Spatial, temporal, and/or procedural } \\
\text { boundaries in which an action is to } \\
\text { be performed* }\end{array}$ & $\begin{array}{l}\text { To ensure sustainability } \\
\text { Within } 24 \text { hours of landing } \\
\text { Annually }\end{array}$ \\
\hline Or else & $\begin{array}{l}\text { Punitive sanction associated with } \\
\text { not performing an action as } \\
\text { prescribed* }\end{array}$ & $\begin{array}{l}\text { Fine of } 10 \text { base salaries } \\
\text { Prison sentence }\end{array}$ \\
\hline
\end{tabular}

*Source: Siddiki et al. 2012

Following the ABDICO syntax, institutional statements can be classified as shared strategies, norms, or rules based on their linguistic structure (Crawford \& Ostrom 1995). Shared strategies adopted by participants have a syntactic structure of AIC/ABIC - strategies involve an aim carried out by an actor or attribute, possibly upon an object, under certain conditions, but are not defined by a deontic, nor do actors face sanctions (or else) when strategies are not adopted. Norms, on the other hand, are characterized by the 
syntactic structure ADIC/ABDIC, because they contain a deontic that defines whether the action is permitted, required, or prohibited. Finally, rules are institutional statements that contain all six linguistic components and have the structure ADICO/ABDICO, because they also contain an explicitly stated sanction (or else) that applies when the prescription is violated. According to Ostrom's (2005) definition, the concept of rules represents the enforcement of prescriptions with respect to a specific deontic, and depends on participants' shared understanding thereof. When used in common parlance and other social sciences, however, rules may refer more broadly to precepts, instructions, regulations, or principles (Ostrom 2005).

Basurto et al. (2010) demonstrated the utility of the IGT syntax by analyzing two pieces of U.S. legislation, one at the national level and one at the state level, by dividing them into individual units of observation, the institutional statements themselves, and coding them according to the ADICO syntax. The IGT approach yields quantifiable measures of the content of legislation (e.g., the number of statements directed at a specific attribute; the number of rules present and the nature of sanctions) and allows the analyst to move forward with a nested analysis of the document-i.e., grouping statements by desired syntactic components to identify biases or emphases in legislation (Basurto et al. 2010). The IGT has also been used to compare formal and informal institutions, and the effect of their interaction on compliance with aquaculture laws in Colorado (Siddiki et al. 2010, Siddiki et al. 2012). Similarly, the aim of this paper is to examine the relationship between the rules-in-form, those explicitly expressed in laws, and the rules-in-use or working rules (Ostrom 2005), as they occur in the management of AMPRs and fisheries in Costa Rica. 


\section{Methods}

\subsection{Selection of Primary Documents}

Because it regulates the behavior of both resource users and organizations involved in the implementation and enforcement of national fishery policies, I analyzed the comprehensive Costa Rican Law of Fishing and Aquaculture (Ley No 8436; Poder Legislativo 2005). The Law of Fisheries and Aquaculture was issued by the nation's legislative assembly in March of 2005 and was drafted by a group of senators through a process that involved extensive political negotiations and over 300 motions for consensus (Cajiao 2005). Several minor reforms of the Law of Fishing and Aquaculture have been approved and published. Two important reforms of the law are considered here to supplement analysis: (1) the reform to Article 9, which alters fishing prohibitions within MPAs and national parks (Poder Legislativo 2010), as well as a social-environmental report produced to examine the implementation of these changes (Corella et al. 2011); and (2) a reform that extends and further specifies the prohibited fishing gear and practices under the major fishing law (Poder Legislativo 2013). In addition, I analyzed a second piece of legislation, an executive decree that outlines the regulations for the creation and implementation of AMPRs (Poder Ejecutivo 2009).

\subsection{Analysis}

Textual analysis of primary documents was carried out using ATLAS.ti (7.0), a type of computer-assisted qualitative data analysis software. I used the software to create a coding system for classifying and organizing institutional statements, dividing them into individual units of observation and their corresponding syntactic elements. Legal 
documents were analyzed according to the procedures outlined in Basurto et al. (2010) and Siddiki et al. (2011). All definitions, preambles, and headings were omitted from coding because they do not represent institutional statements. In Costa Rican legislation, the first and second articles usually comprise a preamble, as they list all legal precedents considered and definitions respectively. In order to identify broader units of observation, the legal documents were divided by sections and subsections, before being divided further into individual institutional statements, which usually consisted of a sentence or part of a sentence. All of the ADICO/ABDICO syntax elements within each sentencebased institutional statement were identified and coded. Special care was taken to ensure that implicit syntactic elements, whether implicit as a result of sentence structure or nested in previous statements, were also coded and included in the analysis. Finally, institutional statements were categorized by their syntactic structure: i.e., statements with the structure AIC/ABIC (strategies), ADIC/ABDIC (norms), and ADICO/ABDICO (rules). Documents were not translated, but rather reviewed in Spanish. Unlike previous studies using the IGT, legal documents were not coded by multiple reviewers, but the results of coding were reviewed three separate times, twice with the help of an additional colleague. The additional reviewer was familiar with linguistic analysis and SpanishEnglish translation, and was trained further on the specific procedures outlined above and the nature of the IGT. While intercoder reliability is important for differentiating some of the specific components (e.g., conditions, or else statements), it does not have a substantial effect on the ability to identify institutional statement types (i.e., norms, strategies, rules) in legislation (Basurto et al. 2010). 
Additionally, I conducted a nested analysis of the data by focusing on specific syntactic elements (Basurto et al. 2010). I analyzed the modal or most frequent deontic components according to attribute groups to which they corresponded in order to identify patterns that may be present. This was of interest because deontic operators have different prescriptive weights—e.g., the "must" deontic is associated with actions that are required, whereas the "may" deontic refers to something that is permitted but not required. Deontic operators were divided according to whether the action they prescribe is obliged, permitted, or forbidden (Crawford and Ostrom 2005). Attributes were grouped in two ways: first, by institutional statements that apply to user groups (e.g., all fishers, sport fishers, commercial fishers, tuna seiners) and statements that apply to government actors; then, specific subsets of these general groups were selected to create a group of attributes for statements that apply to small-scale fishers (i.e. removing attribute codes that only apply to medium- and large-scale fishers), and a group that contains all attributes referring specifically to INCOPESCA (see Table 4). I used Boolean operators in the query analysis tool in ATLAS.ti to determine the number of instances that attribute groups co-occurred with modal deontic operators of interest. Because of the broad nature of classifications and the relatively high intercoder reliability of attribute and deontic components in other studies (Basurto et al. 2010; Siddiki et al. 2012), the lack of multiple coders is not expected to affect the reliability of findings for the nested analysis. 
Table 4. Grouping and modal examples of attribute components for nested analysis.

\begin{tabular}{ll}
\hline Group Name & Examples (frequency) \\
\hline \multirow{3}{*}{ Users } & Fishers (41) \\
& Tuna seiners (27) \\
& Research/educational fishers (9) \\
& Sardine fishers (4) \\
& Fishers (41) \\
Small-scale fishers & Fishing organizations (11) \\
& Permit/license holders (16) \\
& Captain of a vessel (12) \\
& INCOPESCA and related (180) \\
GNG (11) \\
MINAE (10) \\
The state (9) \\
Agencies (5) \\
INCOPESCA (159) \\
Executing agency (10) \\
Representatives of INCOPESCA (2) \\
President of INCOPESCA (1)
\end{tabular}

\subsection{Contextual Information}

It is important that findings obtained from IGT analysis of legislation are evaluated using information about the actors involved, the legal and political context, and the reality of implementation and enforcement on the ground (Sidikki et al. 2012). It is also important to consider the influence of power structures and discourse when applying the IAD framework to a particular problem (Clement 2009). This research is strengthened by careful consideration of the context of AMPR and fishery management in Costa Rica. Specifically, contextual understanding is founded on previous collection and review of government documents, gray literature, and academic literature, as well as qualitative analysis of semi-structured interviews with 23 key informants. Interviews were 
conducted during July and August of 2013. Participants included 15 fishers and community members and two leaders of local community fisher organizations from the villages of Tárcoles and Playa Azul in the Puntarenas province of Costa Rica; three representatives of environmental and sustainable development NGOs (CoopeSoliDar R.L., Fundación MarViva); two representatives of government agencies (INCOPESCA, SNG); and one marine biology professor from the Universidad Nacional de Costa Rica, Puntarenas. Participant selection was purposive and participant-driven (Bernard 2006). In addition to formal interviews, informal interviews were carried out in several locations of the outer Gulf of Nicoya as a means to conduct a rapid rural appraisal (Chambers 1994) of actors' attitudes.

\section{Results}

Data obtained from syntactic coding were summarized by the frequency of each type of institutional statement in the two legal documents (Table 5) and the total number of unique syntactic elements identified (Table 6). Only 18 unique deontic operators were identified across both documents. A summary of modal deontic operators, grouped according to their prescriptive directionality (i.e., permitted, obliged, or forbidden) can be found in Table 7. 'Shall' was the most common deontic operator, identified in 126 units of observation. In Spanish, 'shall' occurs as the future tense of an action verb (the aim) or of an auxiliary verb - i.e. the actor will perform the action. The 'shall' deontic implies that the attribute is obliged to perform the prescribed action, but without explicitly using the word 'must' (deber). Therefore, it has a different connotation and prescriptive weight. 
Table 5. Frequency of institutional statements identified.

(Format adapted from Basurto et al. 2010)

\begin{tabular}{lcc}
\hline Unit of Observation & $\begin{array}{c}\text { Law of Fishing and } \\
\text { Aquaculture }\end{array}$ & $\begin{array}{c}\text { Executive Decree } \\
\text { (AMPR) }\end{array}$ \\
\hline Number of strategies (ABIC) & 24 & 0 \\
Number of norms (ABDIC) & 357 & 32 \\
Number of rules (ABDICO) & 41 & 0 \\
\hline $\begin{array}{l}\text { Total number of units of } \\
\text { observation }\end{array}$ & 422 & 32 \\
\hline
\end{tabular}

Table 6. Frequency of unique syntax components identified in coding.

\begin{tabular}{lc}
\hline $\begin{array}{l}\text { ABDICO } \\
\text { Component }\end{array}$ & $\begin{array}{l}\text { Number of } \\
\text { unique elements }\end{array}$ \\
\hline Attribute & 91 \\
oBject & 122 \\
Deontic & 18 \\
aIm & 351 \\
Condition & 624 \\
Or else & 41 \\
\hline
\end{tabular}

Table 7. Prescriptive types and frequencies of deontic operators.

\begin{tabular}{lll}
\hline Obliged & Permitted & Forbidden \\
\hline & & \\
Must (74) & May (79) & Must not (28) \\
Must, implicit (28) & May, implicit (7) & Prohibited (22) \\
Shall (123) & Authorize (6) & May not (5) \\
Shall, implicit (3) & Permitted (5) & Shall not (2) \\
Oblige (7) & Allow (1) & Will not be \\
Require (5) & Not required (1) & Permitted (1) \\
Require, implicit (1) & & \\
& & \\
\hline
\end{tabular}


A total of 91 unique attribute elements were identified in both documents. The most frequently used attributes included: INCOPESCA, fishers, everyone/anyone, tuna seiners, permit/license holders, and other government agencies (e.g., MINAE, SNG; Table 4). A greater number of unique aim elements were identified (351), which corresponds to the variety of actions prescribed in these laws. The most common aims were: to issue licenses/permits (14) and to establish (e.g., norms, procedures; 11). Fewer of the object elements showed a modal trend. However, INCOPESCA was the object of 9 institutional statements. In all cases, the statement prescribed for other actors to communicate or otherwise be accountable to INCOPESCA for any changes in permitted activities (e.g., landing products in foreign ports, in the case of tuna seiners). Similarly, the majority of conditions were unique, tended to vary with each institutional statement, and exhibit no modal trend. Finally, because they only occur in rules, the kinds of or else statements identified will be discussed in greater detail below.

Norms (ADIC/ABDIC) were the most numerous institutional statement found in the Law of Fishing and Aquaculture $(n=357,87.1 \%)$, as well as in the Executive Decree $(n=32,100 \%)$. Only $24(5.3 \%)$ of all institutional statements identified were shared strategies, and $41(9.03 \%)$ were rules. All the strategies and rules occurred in the Law of Fishing and Aquaculture, while none were identified in the Executive Decree that regulates AMPRs. In previous applications of the IGT, Basurto et al. (2010) and Siddiki et al. (2012) found a similar distribution in the classification of institutional statements (i.e., the majority were norms). In the two legal documents analyzed, norms were used to prescribe a variety of actions by different actors. Examples of norms identified with their corresponding ABDICO syntax elements can be found in Table 8 . 
Table 8. Sample norms with identified ABDICO syntax components.

\begin{tabular}{|c|c|c|}
\hline Document & Text of norm & $\begin{array}{l}\text { ABDICO syntax } \\
\text { components }\end{array}$ \\
\hline $\begin{array}{l}\text { Law of } \\
\text { Fishing and } \\
\text { Aquaculture }\end{array}$ & $\begin{array}{l}\text { Article } 8^{\circ}-\text { Fishing and aquaculture must be } \\
\text { practiced without causing irreparable damages } \\
\text { to ecosystems, without obstructing navigation, } \\
\text { use, and natural flow of waters. }\end{array}$ & $\begin{array}{l}\mathrm{A}=\text { fishers/fish farmers } \\
\mathrm{D}=\text { must } \\
\mathrm{I}=\text { carry out their } \\
\text { activities (implicit) } \\
\mathrm{C}_{1}=\text { without causing } \\
\text { irreparable damages to } \\
\text { ecosystems } \\
\mathrm{C}_{2}=\text { without obstructing } \\
\text { navigation, use, flow of } \\
\text { waters }\end{array}$ \\
\hline $\begin{array}{l}\text { Law of } \\
\text { Fishing and } \\
\text { Aquaculture }\end{array}$ & $\begin{array}{l}\text { Article } 30^{\circ} \text { - Learning or research institutions } \\
\text { that develop educational plans related to fishing } \\
\text { and aquaculture activities must provide an } \\
\text { annual operational plan of activities to } \\
\text { INCOPESCA, to articulate the actions to be } \\
\text { carried out. }\end{array}$ & $\begin{array}{l}\mathrm{A}=\text { learning/research } \\
\text { institutions } \\
\mathrm{B}=\text { to INCOPESCA } \\
\mathrm{D}=\text { must } \\
\mathrm{I}=\text { provide plan of } \\
\text { activities } \\
\mathrm{C}_{1}=\text { when developing } \\
\text { educational plans related } \\
\text { to fishing/aquaculture } \\
\mathrm{C}_{2}=\text { annually } \\
\mathrm{C}_{3}=\text { to articulate actions } \\
\text { to be carried out }\end{array}$ \\
\hline $\begin{array}{l}\text { Executive } \\
\text { Decree } \\
\mathrm{N}^{0} 35502- \\
\text { MAG } \\
\text { (AMPRs) }\end{array}$ & $\begin{array}{l}\text { Article } 7^{\circ}-\text { Of the Vigilance Committees. The } \\
\text { INCOPESCA will promote within fishing } \\
\text { organizations, the formation, training, and } \\
\text { setting up of Vigilance Committees in order to } \\
\text { reach the management and development } \\
\text { objectives in these areas. }\end{array}$ & $\begin{array}{l}\mathrm{A}=\mathrm{INCOPESCA} \\
\mathrm{B}=\text { vigilance } \\
\text { committees } \\
\mathrm{D}=\text { will } \\
\mathrm{I}=\text { promote the } \\
\text { formation, training, } \\
\text { setting up } \\
\mathrm{C}=\text { in order to reach } \\
\text { objectives }\end{array}$ \\
\hline
\end{tabular}


Shared strategies (AIC/ABIC) identified were declaratory in nature and served to establish common understanding with respect to fishing activities. For instance, in Article 76 of the Law of Fishing and Aquaculture, several species are listed specifically (e.g., sailfish, Istiophorus albidius, blue marlin, Makaira indica) and declared to be of public interest for the development of sport and touristic fishing enterprises. No such strategies were employed to declare species that are important for the artisanal fishing sector. A strategy can also be found in Article 123 of the same law, in which all but commercial fishers are declared exempt from import taxes on goods related to fishing activities (e.g., vessels, motors, spare parts, etc.). Another set of strategies outlines the conditions for the expiration of fishing licenses (e.g., once the allotted time on the issued license had passed and no motion had been made to renew it) in Article 113, Law of Fishing and Aquaculture.

Rules (ADICO/ABDICO) were characterized by four kinds of or else statements or punitive sanctions: (1) cancellation or suspension of licenses, permits, authorizations, or concessions for fishing and aquaculture; (2) confiscation of fishing gear or vessels; (3) monetary fines to be paid, defined by a set range of base salaries according to the severity of the violation—one base salary is equivalent to 399,400 colones or $\$ 743.28$ USD (Poder Judicial, 2013); and (4) prison sentences ranging from 2 months to 4 years. Only one rule $(0.02 \%)$ was linked to an attribute that represented a government agency. Specifically, Article 153 in the Law of Fishing and Aquaculture states that any public official or employee who authorizes fishing or aquaculture activities in PAs will be subject to corresponding disciplinary, administrative, and penal sanctions. In contrast, 28 (68.3\%) of the rules identified applied directly to resource users, including commercial 
fishers, anyone conducting any fishing or aquaculture activities, all license or permit holders, and captains of vessels. Of the rules identified, seven applied specifically to commercial fishers (i.e., tuna and sardine seiners) and established sanctions for violations such as landing in foreign ports without proper notice and justification or failing to provide appropriate information about their landings. In contrast, none were specifically directed at the activities of artisanal fishers; i.e., they tended to apply to all fishers. The results of a more specific analysis of attribute groups with respect to modal deontic operators are summarized in Table 9.

Table 9. Nested analysis of attribute groups by modal deontic operators.

\begin{tabular}{|c|c|c|c|c|c|}
\hline \multicolumn{6}{|c|}{ Frequency of institutional statements in each major attribute group } \\
\hline & & Users & $\begin{array}{c}\text { Small-scale } \\
\text { Fishers }\end{array}$ & Government & INCOPESCA \\
\hline \multirow{3}{*}{ 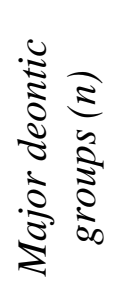 } & Permitted (99) & 18 & 10 & 76 & 63 \\
\hline & Obliged (240) & 87 & 35 & 139 & 109 \\
\hline & Forbidden (68) & 41 & 31 & 4 & 3 \\
\hline \multirow{4}{*}{ 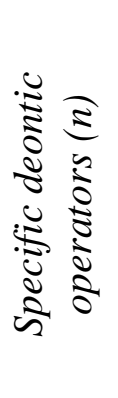 } & Shall (126) & 11 & 7 & 105 & 82 \\
\hline & Must (102) & 64 & 24 & 34 & 27 \\
\hline & May (86) & 13 & 7 & 69 & 59 \\
\hline & May not (38) & 17 & 14 & 1 & 1 \\
\hline
\end{tabular}


The Oblige deontic group was of special interest because of observed differences in the usage of 'shall' and 'must' deontic operators for different attribute groups. In total, 109 institutional statements contained an Oblige deontic directed at INCOPESCA, whereas 35 applied to the Small-scale Fishers group. The implicit, future tense deontic 'shall' was used more frequently when prescribing the actions of government agencies and INCOPESCA, while the 'must' deontic was used more frequently for user groups and small-scale fishers. The percentage of statements with the deontic 'shall' differed significantly $(\mathrm{p}<0.001)$ between the INCOPESCA $(75.2 \%)$ and the Small-scale Fishers (20\%) attribute groups. The difference between the percentage of statements using the 'must' deontic in the INCOPESCA (24.8\%) and SSF (68.5\%) groups was also statistically significant $(\mathrm{p}<0.001)$.

Deontic operators in the Permitted group were associated with the Government group more often than they were with the Users group. Meanwhile, the Forbidden deontic operators were used to a substantially greater extent when referring to the Users group than the Government group. For both the Permitted and Forbidden deontic groups, differences observed were statistically significant $(\mathrm{p}<0.001)$. More specifically, the Permitted deontic 'may' was more commonly applied to the Government group (83.3\%) as opposed to the Users group (8.7\%); and the Forbidden deontic 'must not' was directed more often at the Users group (65.4\%) than the Government group (2.6\%). Proportional differences for the 'may' and 'must not' deontic operators were also statistically significant at the $\alpha=0.001$ level. 


\section{Discussion}

Several interesting findings have emerged from this application of the IGT, all of which require an informed discussion with consideration of contextual factors, different levels of governance, and informal institutions. On one hand, the vast majority of institutional statements identified in the examined legislations were norms, which carry no explicitly stated sanction. The prevalence of norms, which was also characteristic of previous applications of the IGT, may reflect the shortcomings of this analytical method for capturing the implicit and comprehensive nature of sanctioning mechanisms. It is possible that or else elements are implicit as a result of broader frameworks for accountability and the nested nature of legislation (Basurto et al. 2010). In the Law of Fishing and Aquaculture, for instance, sanctions were not explicitly stated in each article but summarized in a separate clause (i.e., Section X, Chapter I). In the case of the Executive Decree for the regulation of AMPRs, sanctions are expressed in one inclusive statement (Article 14, Poder Ejecutivo 2009), which prescribes that authorities follow the sanctions outlined in the broader Law of Fishing and Aquaculture. In order to improve the current methodology, it would be beneficial to separate various clauses of the legislation and identify overarching sanctions that would result from the violation of each institutional statement, but which may not be explicitly listed in each article.

The overwhelming majority of sanctions found in statements classified as rules were directed at user groups, while virtually none addressed the regulating agencies. The difference is considerable, given that approximately $54 \%$ of all institutional statements prescribed actions to be carried out by government agencies specifically (Table 9), and a greater number of statements with Oblige deontic operators were directed at the 
Government attribute group. The asymmetry in explicit sanctions could suggest an absence of mechanisms for government accountability, at least as inscribed in the Law of Fishing and Aquaculture. However, the explicit purpose of legislation is to define the behavior of citizens and user groups, while government accountability is often nested in larger systems of authority. The government of Costa Rica is a democratic republic with Executive, Legislative, and Judicial powers that are ostensibly mutually accountable. As a decentralized entity of the Executive Power, formerly part of the Ministry of Agriculture, INCOPESCA is accountable to the presidential cabinet and to independent overseeing agencies such as the National Comptroller's Office (Poder Legislativo 1994). Nonetheless, it is unclear whether viable mechanisms exist to bring INCOPESCA to accountability to its less powerful constituents, other than petitioning the Office of the Ombudsman (Solís Rivera, V., interview 2013), a process that increases transaction costs for already vulnerable actors seeking conflict resolution.

With regards to AMPRs, Executive Decree No 35502-MAG (Poder Ejecutivo 2005) establishes a set of norms and strategies to be followed for their creation and implementation. Upon analysis, the decree imposes onerous requirements of communities or fishing organizations seeking to protect a marine area from commercial and exploitative fishing — onerous because the communities that seek the AMPR designation tend to struggle for subsistence, living below the poverty line (e.g., communities in Chira, Babeu et al. 2013), and also tend to lack the education (Solís Rivera et al. 2010) that may be necessary to draft the initial request and management plan without support. The information that is required in an AMPR application includes: evidence of the biological, fishing, sociocultural, and environmental benefits that merit the establishment of the 
AMPR; baseline information on the socioeconomic status of the community; appropriate mapping according to national standards; and participatory zoning for determining permitted gear types (Poder Ejecutivo 2009). The University of Costa Rica was poised to charge a fishing cooperative in Tárcoles approximately $\$ 7,000$ to conduct investigations, which they could not afford; the organization decided to undertake them independently with the oversight of INCOPESCA and the help of an external cooperative, CoopeSoliDar R.L. (Chacón, D., interview 2013). Currently, the creation of AMPRs depends on the support of external NGOs (e.g., Fundación MarViva, CoopeSoliDar R.L.), and while it is available to some communities, it cannot suffice as a mechanism for addressing the human rights of communities whose livelihoods are threatened by resource scarcity, and who cannot move on to richer waters in commercial vessels.

In my analysis of the Law of Fishing and Aquaculture, two other findings suggest an emphasis on protecting national economic interests related to commercial fishing. First, the various rules that apply to commercial fishers, specifically tuna seiners and sardine vessels, reflect an emphasis on production and preventing of losses to the national industry (e.g., processing and canneries). One rule imposes a monetary fine for seiners that fail to install required satellite monitoring systems, but the others involve sanctions for landing products in foreign ports or not producing for the length of issued permits. On the other hand, no specific statements with punitive sanctions target small-scale fishers specifically. The second finding is that commercial fishers enjoy greater economic incentives than small-scale fishers. All receive the same fuel subsidies, according to a provision in the Law of Fishing and Aquaculture, which are harmful for the management of an already poorly regulated industry. Fuel exoneration and other harmful subsidies 
(e.g., boat construction, infrastructure development) are commonly practiced and supported by government funding in Costa Rica; they are detrimental because they promote overexploitation and encourage fishing even when stocks are declining and when it is not otherwise profitable (Sumaila and Pauly 2006). Additionally, Article 55 of the Law of Fishing and Aquaculture establishes an economic incentive (i.e., a continued renewal of fishing licenses without fees) for tuna seiners who turn in the entirety of their landings to national processing plants and canneries.

The result, as Pacheco (2005) points out, is that foreign tuna seiners are encouraged to keep exploiting Costa Rican waters to the detriment of national tuna fishers. This kind of incentive for increased production is not surprising considering the post-harvest sector generates $77 \%$ of fisheries jobs in Costa Rica (Turriago 2013). It is also consistent with trends of increased processing- and export-driven production associated with the neoliberalization of global and regional markets (Béné et al. 2007). In the region of Central America, exports account for approximately $85 \%$ of the commercial balance (Turriago 2013). However, while the nation's exportation of fisheries products has increased rapidly in recent years, the amount being imported to supplement domestic consumption is greater, which may stem from increasing scarcity in the face of demand (Calderón et al. 2013; Turriago 2013). There are also differences in the punitive sanctions for national and foreign vessels that unload landings of shark fins not properly attached to the trunk (Article 139). Specifically, national fishers are punished with fines and prison sentences while foreign vessels are only fined. The difference stems from the agreements made in the United Nations Convention on the Law of the Sea (UNCLOS), in which nations cannot impose imprisonment sanctions beyond the 12 miles of territorial waters 
(Cajiao 2005). Nonetheless, the difference in deterrent sanctions is an obstacle for preventing finning and illegal fishing at the hands of foreign ships.

Finally, the finding that 'shall' and 'must' deontic operators were deployed differently for the Users and Government groups suggests an asymmetry in the political and legal discourse. In previous work with the IGT (i.e., Basurto et al. 2010) the deontic operators 'shall' and 'must' have been used interchangeably, as they signify the same type of prescription (i.e., Oblige). However, because of their differing connotations and the absence of sanctions for government agencies' non-compliance, the two types of deontic convey different meanings for the subjects who are bound by legislation. According to applications of game theory, the interpretation of deontics depends on a rational appraisal of trade-offs - i.e., the costs and benefits of complying with versus defecting from a prescription (Crawford and Ostrom 2005). The costs of violating a given prescription are therefore related to the certainty of sanctions, and possibly also whether the deontic is explicit and forceful as opposed to implicit and passive.

In the context of critical theory, discourse refers to the various factors, linguistic and non-linguistic (e.g., social practices, values), that shape and are shaped by power dynamics and social institutions (Schiffrin et al. 2001). Legal and political forms of discourse are influential partly because they are formulated by powerful social groups (i.e., politicians, in this case), and because they are employed as a means to shape knowledge, attitudes, and behavior (Van Dijk 2001). The direct objective of policy is to affect the behavior of target groups using prescriptive language. The Costa Rican Law of Fishing and Aquaculture, as mentioned previously, was drafted by senators in the Legislative Assembly of Costa Rica, a group that differs markedly from some of the user 
groups it legislates in terms of class, education, gender, etc. Legislators have power over the subjects affected by the discourse and policies they produce: the consequences to fishers for not accepting legal discourse and adopting its prescriptions are explicitly stated in the text (e.g., fines, imprisonment); however, the same consequences are not explicitly stated for government actors. The nature of prescriptive language in policy can also be influenced by social constructions of target groups, as Schneider and Ingram (1993) initially pointed out. In addition, Dixon and Hapke (2003) described how utilitarian and geographically specific values about farmers, productivity, and the economy have shaped agrarian policy in the United States. Béné (2003) explored some of the social constructions that have influenced perceptions of fishers, specifically regarding their poverty, which stem in part from generalizations of seminal work on the failures of open-access resources (i.e., Gordon 1954; Hardin 1968).

In one of the interviews conducted for this project, an employee of INCOPESCA cited fishing pressure from the small-scale sector as a primary reason for overexploitation of marine resources in Costa Rica, but failed to mention the impacts of any commercial fishing activity. The informant also cited illegal fishing as a major problem in the implementation of AMPRs, while all other informants emphasized the lack of government involvement as a greater obstacle. The difference in attitudes between a member of the enforcement agency and those expressed by small-scale users and conservation stakeholders indicates a discrepancy in shared meaning about problems in management, as well as common objectives. It is possible that government stakeholders' attitudes shape the kinds of regulations implemented by INCOPESCA, but determining that relationship is beyond the scope of the present work. It would be necessary to 
conduct a more extensive survey of attitudes among a wider range of government stakeholders, including legislators and members of other agencies involved. Additionally, the aforementioned differences in attitudes pertain more to the regulatory actions of INCOPESCA as an independent agency and to possible differences in enforcement, rather than to the effects of social constructions on legislation. Determining the influence of broader cultural discourse on legislation is difficult, but the inequalities that have resulted from fisheries regulations and their enforcement in Costa Rica merit further investigation and resolution.

Although INCOPESCA is the agency charged with carrying out the majority of prescriptions in the Law of Fishing and Aquaculture, it has failed to comply with its numerous responsibilities. It is important to acknowledge that INCOPESCA is severely limited by budget and personnel constraints (Alpízar 2006; B. Marín, interview, 2013). There are approximately 140 employees working for INCOPESCA in all of Costa Rica (Marín, B., INCOPESCA, interview 2013), a number that is clearly inadequate for an agency charged with regulating fisheries within $613,683 \mathrm{~km}^{2}$ of jurisdictional waters (FAO 2004). However, five institutional and community informants interviewed — all of whom interact extensively with INCOPESCA for the purposes of conservation planning, AMPR implementation, and permitting - have suggested that financial constraints are not to blame for all of the agency's problems. Specifically, informants reported that while some of the agency's personnel are largely supportive and helpful, there is a general unwillingness to cooperate with stakeholders, especially the artisanal fleet.

In addition, several informants interviewed reported that INCOPESCA have introduced sudden and unannounced changes to the requirements or costs of renewing 
fishing licenses, rendering many fishers' activities illegal—such a practice would represent a discrepancy between stated national values of social sustainability and the agency's practices, but INCOPESCA has jurisdiction over such regulations at the operational level. It is also possible that fishers' perceptions of shifts in regulation are influenced by gaps in information and communication; it would be important to establish a clearer measure of changes in informal institutions in order to make any conclusive remarks about differential enforcement. Nonetheless, the agency has failed to bring a number of semi-industrial fishing vessel owners to accountability for trawling in MPAs, which is illegal under the Law of Fishing and Aquaculture. In response to negligence with respect to these cases, as well as their failure to disclose requested information of public nature, the environmental NGO PRETOMA filed a lawsuit in the nation's Constitutional Court against Luís Dobles Ramírez, the former Executive President of INCOPESCA, in February of 2012 (PRETOMA 2013).

INCOPESCA has also been accused of corruption and conflicts of interestnamely, that its Board of Directors is catering to the interests of the shrimp trawler industry, in which they have personal investments (PRETOMA 2014). Fundación MarViva, another marine conservation NGO, recently filed an appeal for the protection of constitutional rights (recurso de amparo) to the same court (Sala IV) against INCOPESCA, for renewing the licenses of several shrimp trawling vessels (Solano 2014). In doing so, INCOPESCA has gone against the court's recent resolution that declared trawling unconstitutional because it goes against the nation's values of sustainability, and discouraged the issue or renewal of any more licenses. The court's ruling is now been challenged by a bill that would permit 'sustainable' trawling, which 
has already received approval in the Puntarenas regional Legislative Assembly. The bill is the most recent pull in what seems like a tug of war, with commercial interests and INCOPESCA on one side and environmental NGOs and small-scale fishers on the other, and it is already being contested for its failure to fully address the social and ecological impacts of the trawling industry (PRETOMA 2014).

Similarly, the SNG is the sole agency with police competencies, charged with monitoring all jurisdictional waters for drug trafficking vessels, illegal fishing, and a number of other duties (C. Morales, interview 2013). The agency is also limited in financial and human resources: it counts with an annual budget of approximately 7,000 million colones ( $\sim 12 \mathrm{M}$ USD) and 500 employees; it only manages to secure coverage of $40 \%$ of coastlines, $25 \%$ of the territorial waters, and $0.05 \%$ of the EEZ, and must prioritize the prevention of drug trafficking (C. Castro Moralers, interview, 2013). According to several fishers interviewed, SNG officials stop and inspect the activities of small-scale fishers more frequently than those of commercial fishers such as shrimp trawlers. It is possible that ease of access and convenience influence the enforcement practices of SNG officials. Moreover, the SNG has the power to confiscate all gear from unlicensed fishers and unauthorized gear from licensed fishers. During informal interviews, several respondents claimed that SNG officials were targeting small-scale fishers, confiscating their nets, and subsequently selling them to fishers during unofficial auctions. Two other respondents claimed that some SNG officials are corrupt and are involved in drug trafficking operations. Several coastguard officers have indeed been arrested and investigated for links to drug trafficking (e.g., see Cerdas 2013), including the former chief of the SNG (Aguerdas 2013). However, fishers' claims are not readily 
supported simply through analysis of the legal framework, which only comprises formal institutions. It would be necessary to obtain more context-specific empirical evidence in order to examine the relationship between formal institutions (i.e., legislation) and more informally adopted enforcement practices on the ground.

\section{Conclusions}

The current application of the IGT for analyzing fishing legislation in Costa Rica has been useful for illustrating some important regulatory problems, which are supported by a contextual understanding of management in the Gulf of Nicoya. Nonetheless, there are several limitations to this study, which are worth noting in the discussion of its applicability for future research. As mentioned previously, the majority of institutional statements were classified as norms, which may result from the linguistic segmentation of institutional statements - a more inclusive methodology must be developed in order to account for implicit sanctioning mechanisms. In addition, the initial hypothesis that legislation would reflect reported biases against small-scale fishers was not supported solely by linguistic analysis of the legal text. Because enforcement practices are rooted in informal institutions, a more comprehensive survey of informally adopted prescriptions must be carried out in order to determine their relationship to those examined here. Similarly, although a nested analysis of modal deontic operators and attribute groups revealed a significant asymmetry, a survey of attitudes among legislators and other government stakeholders would be necessary to empirically demonstrate a relationship between social constructions of users and the production of legal discourse. Lastly, the analysis should be extended to several other pieces of legislation important for the 
regulation of marine fisheries and MPAs, such as the 1998 Law On Biodiversity and the Law for the Creation of INCOPESCA (Poder Legislativo 1994).

Punitive sanctions identified in the examined legislation applied almost exclusively to user groups, which is consistent with the role of policy in regulating the behavior of users. However, mechanisms for ensuring the accountability of government agencies were not identified in any of the legislation examined, including the Law For the Creation of INCOPESCA. Moreover, the Executive Decree for the creation and implementation of AMPRs was distinct in the sense that it conferred considerably more responsibilities to small-scale fishers. As a policy instrument, it effectively facilitates the devolution of rights and responsibilities over management in AMPRs to fishing commnities, but it fails to address the obstacles faced by these less powerful actors in gaining recognition and fulfilling the requirements for protection (e.g., collection of technical and scientific information). In addition, the many shortcomings of regulatory agencies are distinct obstacles for successful participatory management in Costa Rica.

Recently, an association of public research universities (Presidencia de la República de Costa Rica 2012; Mug 2013) and a special presidential commission on marine governance (Anon. 2012) have issued reports in which they recommended major changes to INCOPESCA and its constituting legislation. The reports echo the demands of environmental NGOs such as PRETOMA and MarViva, as well as the conclusions reached in Chapter II of my thesis. In particular, they suggest removing or changing the structure of the Board of Directors in order to reduce the weight of fishing stakeholders' input on decision-making. In this regard, it should be noted that while action must be taken to ensure that commercial fishing interests do not define the nature of fisheries 
management, part of the solution must also be to continue to incorporate the voices of small-scale fishers in decision-making. The livelihoods of the thousands of small-scale fishers in Costa Rica have already been compromised by imprudent planning of MPAs and commercial overfishing, and their contributions have clear potential for the conservation of marine resources, as evidenced by the initiatives of several communities to establish AMPRs.

Fortunately, a recent reform of the Law of Fishing and Aquaculture makes it legal for artisanal fishers to fish using low-impact gear in some of the internal waters in MPAs under the management of MINAE (Poder Legislativo 2010), and fishing communities on the Nicoya Peninsula are working with PRETOMA to establish the first Marine Management Area, a newly recognized MPA model that permits sustainable, small-scale fishing (PRETOMA 2013). The Marine Management Area will provide a haven for the critically endangered hawksbill sea turtle (Eretmochelys imbricata), as well as species of commercial significance currently being overexploited (PRETOMA 2013). The work ahead lies in strengthening existing institutions, continually evaluating and improving management efforts, and promoting cooperation among communities, the state and these important private organizations. 


\section{REFERENCES}

Abler, D. G., A. Rodríguez, and J. S. Shortle. 1999. Trade liberalization and the environment in Costa Rica. Environment and Development Economics, null (3): 357-373.

Adger, N. W. 2003. Social capital, collective action, and adaptation to climate change. Economic Geography, 79: 387-404.

Aguerdas, C. 2013. Jefe de Guardacostas de Quepos cae en manos de la Policía sospechoso de estar vinculado con el narcotráfico. La Nación, 05/01/2013. Available from: www.nacion.com (Accessed March 2013).

Allison, E. H., and F. Ellis. 2001. The livelihoods approach and management of smallscale fisheries. Marine Policy, 25: 377-388.

Alpízar, M. A. Q. 2006. Participation and fisheries management in Costa Rica: From theory to practice. Marine Policy, 6: 641-650.

Alvarado, J. J., J. Cortés, M. F. Esquivel, and E. Salas. 2012. Costa Rica's marine protected areas: status and perspectives. Revista de Biología Tropical, 60(1): 129142.

Álvarez, J., and E. Ross. 2010. La Pesca de Arrastre en Costa Rica. Fundación MarViva, San José, Costa Rica.

Anderies, J. M., M. A. Janssen, and E. Ostrom. 2004. A framework to analyze the robustness of social-ecological systems from an institutional perspective. Ecology and Society, 9(1): 18.

Anderson, L. G., and M. C. Holiday. 2007. The design and use of Limited Access Privilege Programs. NOAA Technical Memorandum NMFS-F/SPO-86. U.S. Department of Commerce, National Oceanic and Atmospheric Administration, National Marine Fisheries Service, Hallandale, FL, USA. Available from: http://www.pacificwhiting.org/images/design_and_useLAPs2007.pdf (Accessed June 2014).

Anon. 2012. Comisión Presidencial Para la Gobernanza Marina: Informe Final. Presidencia de la República de Costa Rica. Available from: http://www.cimar.ucr.ac.cr/PDFS/Informe-Final_Comision-GobernanzaMarina.pdf (Accessed March 2014).

Araya, S. S. 2013. Situación actual de la pesca artesanal en Costa Rica. Anuario de Estudios Centroamericanos, Universidad de Costa Rica, 39: 311-342. 
Armitage, D. R., R. Plummer, F. Berkes, R. I. Arthur, A. T. Charles, I. J. Davidson-Hunt, A. P Diduck, N. C. Doubleday, D. S. Johnson, M. Marschke, P. McConney, E. W. Pinkerton, and E. K. Wollenberg. 2009. Adaptive co-management for socialecological complexity. Frontiers in Ecology and the Environment 7: 95-102.

Babeu, A., K. Cabral, and J. Hartmann, K. Poti. 2012. Establishing socioeconomic baselines of sustainable fishing communities: A study of the fishermen of Palito and Montero. Interactive Qualifying Report, Worcester Polytechnic Institute. Fundación MarViva, San José, Costa Rica. Available from: http://web.cs.wpi.edu/ rek/Projects/MarViva_B12.pdf (Accessed March 2014).

Basurto, X., S. Gelcich, and E. Ostrom. 2013. The social-ecological system framework as a knowledge classificatory system for benthic small-scale fisheries. Global Environmental Change, 23: 1366-1380.

Basurto, X., G. Kingsley, K. McQueen, M. Smith, and C. M. Weible. 2010. A systematic approach to institutional analysis: Applying Crawford and Ostrom's grammar. Political Research Quarterly, 63: 524-537.

Basurto, X. and E. Ostrom. 2009. Beyond the Tragedy of the Commons. Economia delle fonti di energia e dell'ambiente 52: 35-60.

Beddington, J. R., D. J. Agnew, and C. W. Clark. 2007. Current problems in the management of marine fisheries. Science 316: 1713-1716.

Béné, C. 2003. When fishery rhymes with poverty: A first step beyond the old paradigm on poverty in small-scale fisheries. World Development, 31: 949-975.

Béné, C., G. Macfadyen, and E. H. Allison. 2007. Increasing the contribution of smallscale fisheries to poverty alleviation and food security. FAO Fisheries Technical Paper, $\mathrm{N}^{\mathrm{o}}$. 481. FAO, Rome, Italy.

Berkes, F. 2009. Evolution of co-management: role of knowledge generation,bridging organizations and social learning. Journal of Environmental Management, 90: 1692-1702.

Berkes, F., J. Colding, and C. Folke, editors. 2003. Navigating social-ecological systems: Building resilience for complexity and change. Cambridge University Press, New York, USA.

Berkes, F., and C. Folke, editors. 1998. Linking social and ecological systems: Management practices and social mechanisms for building resilience. Cambridge University Press, New York, USA. 
Bernard, H. R. 2006. Research methods in anthropology: Qualitative and quantitative approaches, $4^{\text {th }}$ edition. Altamira Press, New York, New York, USA.

Birner, R. and H. Wittmer. 2003. Using social capital to create political capital. Pages 291-334 in N. Dolsak and E. Ostrom, editors. The Commons in the New Millennium: Challenges and Adaptations. MIT Press, Cambridge, MA, USA.

Borrini-Feyerabend, G., N. Dudley, T. Jaeger, B. Lassen, N. P. Broome, A. Phillips, and T. Sandwith. 2013. Governance of Protected Areas: From understanding to action. Best Practice Protected Area Guidelines Series No. 20. IUCN, Gland, Switzerland.

Breton, Y. 1991. Economic anthropology and interdisciplinarity in Costa Rica fishing: the pitfalls of problem formulation. Maritime Anthropological Studies, 4(1): 1-12.

Cajiao, V. 2005. Reseña de la nueva Ley de Pesca y Acuicultura. Ambientico, 139: 6-8. Ambientico Ediciones, Heredia, Costa Rica.

Calderón, J. C., E. Céspedes, M. Chacón, K. López, C. Medaglia, E. Mora, F. Vargas, J.M. Vargas, and L. C. Vargas. 2013. Estadísticas de comercio exterior de Costa Rica de 2012. Promotora del Comercio Exterior de Costa Rica (PROCOMER). San José, Costa Rica.

Carlsson, L., and F. Berkes. 2005. Co-management: concepts and methodological implications. Journal of Environmental Management, 75: 65-76.

Cerdas, D. 2013. Detienen a capitán de guardacostas de Golfito con $\$ 64.000$ en su habitación. La Nación, 07/17/2013. Available from: http://www.nacion.com/sucesos/narcotrafico/guardacostas-Golfitonarcotrafico_0_1354264683.html (Accessed March 2014).

Chacón, A., H. Araya, A. Vásquez, R. Brenes, B. Marín, J. Palacios, R. Soto Rojas, F. Mejía-Arana, Y. Shimazu, K. Hiramatsu. 2007. Fishery Statistics for the Gulf of Nicoya, Costa Rica 1994-2005. Project for the sustainable fisheries management in the Gulf of Nicoya. INCOPESCA, UNA, JICA. Puntarenas, Costa Rica.

Chambers, R. 1994. The origins and practice of participatory rural appraisal. World Development, 22: 953-969.

Clement, F. 2010. Analysing decentralised natural resource governance: proposition for a "politicised" institutional analysis and development framework. Policy Sciences, 43: $129-156$. 
CoopeSoliDar R.L. 2006. Tárcoles: Una comunidad de pescadores artesanales en Costa Rica. Aportes a la conservación de los recursos marino-costeros del Golfo de Nicoya. CoopeSoliDar, R.L., San José, Costa Rica.

2007. Consideraciones sociales del sector pesquero artisanal sobre el Corridor Marino de Conservación del Pacífico Este Tropical: primeras ideas para la incidencia social. CoopeSoliDar R.L., San José, Costa Rica.

2009. Pesca artesanal responsable: Aportes a la conservación de la diversidad marino-costera. Surgimiento de actividades económicas alternativas para la participación de este sector en el desarrollo local en el Pacífico de Costa Rica. CoopeSolidar, R. L., San José, Costa Rica.

2010a. Tárcoles +5: Línea de base de la comunidad de Tárcoles. CoopeSoliDar R.L., San José, Costa Rica.

_ 2010b. Plan de ordenamiento de la pequeña pesquería: Área marina de pesca responsable de Tárcoles. CoopeSoliDar R.L., San José, Costa Rica.

_2013. Fortaleciando la gobernanza marina desde las comunidades de pesca artesanal: Áreas marinas de pesca responsable y la vision desde sus protagonistas del mar. CoopeSoliDar R.L., San José, Costa Rica.

Corella, R. X. R., G. V. Rojas, and G. V. Rodriguez. 2011. Informe Socioambiental: Reforma del artículo 9 de la Ley de Pesca y Acuicultura $\mathrm{N}^{\circ} 8436$ de $1^{\circ}$ de Marzo de 2005. Proyecto de Ley, Expediente No 17.715, ST.248-2011 SA. San José, Costa Rica.

Cox, M., G. Arnold, and S. V. Tomás. 2010. A Review of design principles for community-based natural resource management. Ecology and Society, 15(4): 38.

Crawford, S. E. S., and E. Ostrom. 1995. A grammar of institutions. The American Political Science Review, 89(3): 582-600.

- 2005. A grammar of institutions. Pages 137-174 in E. Ostrom. Understanding Institutional Diversity. Princeton University Press, Princeton, NJ, USA.

Cudney-Bueno R, Basurto X (2009) Lack of cross-scale linkages reduces robustness of community-based fisheries management. PLoS ONE 4(7): e6253.

Deacon, R. T. 2012. Fishery management by harvester cooperatives. Review of Environmental Economics and Policy, 6: 258-277. 
Defeo, O., M. Castrejón, L. Ortega, A. M. Kuhn, N. L. Gutiérrez, and J. C. Castilla. 2013. Impacts of climate variability on Latin American small-scale fisheries. Ecology and Society, 18(4): 30.

Dewees, C. M. 1989. Assessment of the implementation of individual transferable quotas in New Zealand's inshore fishery. North American Journal of Fisheries Management, 9: 131-139.

Dixon, D. P., and H. M. Hapke. 2003. Cultivating discourse: The social construction of agricultural legislation. Annals of the Association of American Geographers, 93: 142-164.

Dongol, Y., and J. T. Heinen. 2012. Pitfalls of CITES Implementation in Nepal: A Policy Gap Analysis. Environmental Management, 50: 181-190.

Evans, L., N. Cherrett, and D. Pemsl. 2011. Assessing the impact of fisheries comanagement interventions in developing countries: A meta-analysis. Journal of Environmental Management, 92: 1938-1949.

FAO. 1995. Code of conduct for responsible fisheries. FAO, Rome, Italy. 2004. Fishery Country Profile: Republic of Costa Rica. Available from: http://www.fao.org/fi/oldsite/FCP/en/cri/profile.htm (Accessed March 2014).

_2012. The State of World Fisheries and Aquaculture. FAO, Rome, Italy.

FAO and World Fish Center. 2008. Small-scale capture fisheries: A global overview with emphasis on developing countries. A Preliminary Report of the Big Numbers Project. FAO, Rome, Italy.

Folke, C. 2006. Resilience: The emergence of a perspective for social-ecological systems analyses. Global Environmental Change, 16: 253-367.

Folke, C., J. Colding, and F. Berkes. 2003. Synthesis: building resilience and adaptive capacity in social-ecological systems. Pages 352-387 in F. Berkes, J. Colding, and C. Folke, editors. Navigating Social-Ecological Systems: Building Resilience for Complexity and Change. Cambridge University Press, New York, NY, USA.

Fundación MarViva. 2013. Casi 30 años después: Veda anual en el Golfo de Nicoya no ha dado resultados. Notes archive. Available from: http://www.marviva.net/index.php/es/noticias/archivo-de-notas/406-casi-30-anosdespues-veda-anual-en-el-golfo-de-nicoya-no-ha-dado-resultados (Accessed April 2014). 
Gallardo, D. B. 2009. Coastal artisanal fisheries and community conservation in Costa Rica. Masters Thesis (Environment and Sustainable Development). International Institute of Social Studies, The Hague, Netherlands.

Gordon, S. H. 1954. The economic theory of a common property resources: the fishery. Journal of Political Economy, 62: 124-142.

Gutiérrez, N. L., R. Hillborn, and O. Defeo. 2011. Leadership, social capital and incentives promote successful fisheries. Nature, 470: 386-389.

Hansen, C. D. 2005. Grounded theory research methods. Pages 265-280 in R. A. Swanson, E. F. Holton III, editors. Research in Organizations: Foundation and Methods of Inquiry. Berrett-Koehler, San Francisco, California, USA.

Hardin, G. 1968. The tragedy of the commons. Science, 162: 1243-1248.

Heinen, J. T. 2010. The importance of a social science research agenda in the management of protected natural areas, with selected examples. Botanical Review, 76: 140-176.

Heinen, J. T., and R. Shestha-Acharya. 2011. The non-timber forest products sector in Nepal: Emerging policy issues in plant conservation and utilization for sustainable development. Journal of Sustainable Forestry, 30: 543-563.

Kittinger, J. N., E. M. Finkbeiner, N. C. Ban, K. Broad, M. H. Carr, J. E. Cinner, S. Gelcich, M. L. Cornwell1, J. Z. Koehn, X. Basurto, R. Fujita, M. R. Caldwell, and L. B. Crowder. 2013. Emerging frontiers in social-ecological systems research for sustainability of small-scale fisheries. Current Opinion in Environmental Sustainability, 5: 352-357.

Imperial, M. T., and T. Yandle. 2005. Taking institutions seriously: Using the IAD framework to analyze fisheries policy. Society and Natural Resources, 18: 493509.

INCOPESCA. 2011. AJDIP No 193-2011. Establece Área Marina de Pesca Responsable de Tárcoles. La Gaceta No 159, 08/19/11. San José, Costa Rica.

—. 2012. AJDIP No 154-2012. Amplía Área Marina de Pesca Responsable de Palito hacia Montero, Isla de Chira. La Gaceta N 169, 8/22/12. San José, Costa Rica.

Jentoft, S., B. J. McCay, and D. C. Wilson. 1998. Social theory and fisheries comanagement. Marine Policy, 22: 423-436.

Kittinger, J. N., E. M. Finkbeiner, N. C. Ban, K. Broad, M. H. Carr, J. E. Cinner, S. Gelcich, M. L. Cornwell1, J. Z. Koehn, X. Basurto, R. Fujita, M. R. Caldwell, and 
L. B. Crowder. 2013. Emerging frontiers in social-ecological systems research for sustainability of small-scale fisheries. Current Opinion in Environmental Sustainability, 5: 352-357.

Liu, J., T. Dietz, S. R. Carpenter, C. Folke, M. Alberti, C. L. Redman, S. H. Schneider, E. Ostrom, A. N. Pell, J. Lubchenco, W. W. Taylor, Z. Ouyang, P. Deadman, T. Kratz and W. Provencher. 2007. Coupled human and natural systems. AMBIO, 36(8): 639-649.

Mack, S., B. Epler, P. Atelsek, and D. Dudenhoefer. 1992. Profile of the coastal resources of Costa Rica. Pages 62-97 in G. Foer and S. Olsen, editors. Central America's coasts: Profiles and an agenda for action. USAID and Coastal Resource Center, University of Rhode Island. Narragansett, RI, USA. Available from: http://pdf.usaid.gov/pdf_docs/PNABN396.pdf (Accessed March 2014).

Madrigal, P. and V. Solís Rivera. 2012. Recognition and Support of ICCAs in Costa Rica. In A. Kothari, C. Corrigan, H. Jonas, A. Neumann, and H. Shrumm, eds. Recognising and Supporting Territories and Areas Conserved By Indigenous Peoples And Local Communities: Global Overview and National Case Studies. Technical Series No. 64.Secretariat of the Convention on Biological Diversity, ICCA Consortium, Kalpavriksh, and Natural Justice, Montreal, Canada.

Marín Cabrera, M. 2012. Identificación y caracterización de actores institucionales y de la sociedad civil claves en la gestión de las AMUM Golfo de Nicoya y Pacífico Sur. Proyecto SINAC-BID-MarViva, Manejo integrado de los recursos marinocosteros en la Provincia de Puntarenas. San José, Costa Rica. 103 pp.

Mascia, M. B., and C. A. Claus. 2008. A property rights approach to understanding human displacement from protected areas: the case of marine protected areas. Conservation Biology, 23: 16-23.

McCay, B. 2004. ITQs and community: An essay on environmental governance. Agricultural and Resource Economics Review 33: 162-170.

Merino, G., M. Barange, and C. Mullon. 2010. Climate variability and change scenarios for a marine commodity: Modelling small pelagic fish, fisheries and fishmeal in a globalized market. Journal of Marine Systems, 81: 196-205.

Mug, M. 2013. Gestión marino-costera. Ponencia preparada para el Decimonoveno Informe Estado de la Nación. Programa Estado de la Nación, San José, Costa Rica.

Ohashi, T. 2010. Challenges faced by U.S. fishery policy in overcoming overfishing in federally managed waters: Shifting from traditional to responsible fishery 
management for sustainable seafood. The Japanese Journal of American Studies 21: $189-210$.

Ostrom, E. 1990. Governing the commons: The evolution of institutions for collective action. Cambridge University Press, New York, NY, USA.

2005. Understanding Institutional Diversity. Princeton University Press, Princeton, NJ, USA.

_ 2007. Institutional rational choice: An assessment of the institutional analysis and development framework. Pages 21-64 in P. A. Sabatier, editor. Theories of the Policy Process, $2^{\text {nd }}$ ed. Westview: Boulder, CO, USA.

2009. A general framework for analyzing sustainability of social-ecological systems. Science, 325: 419-422.

2010. Beyond markets and states: Polycentric governance of complex economic systems. American Economic Review, 100 (June 2010): 1-33.

2011. Background on the Institutional Analysis and Development Framework. The Policy Studies Journal, 39(1): 7-27.

Ovares, L. L. 1989. El desrrrollo cooperrativista en los pescadores artesanales del Golfo de Nicoya, Costa Rica. Revista ABRA, 9(11-12): 7-30.

Pacheco, F. 2005. ¿Nueva Ley de Pesca? Ambientico, 139: 10-11. Ambientico Ediciones, Heredia, Costa Rica.

Pauly, D., J. Alder, E. Bennett, V. Chsitensen, P. Tyedmers, and R. Watson. 2003. The future for fisheries. Science, 302: 1359-1361.

Pauly, D., V. Christensen, J. Dalsgaard, R. Froese, and F. Torres, Jr. 1998. Fishing down marine food webs. Science, 279: 860-863.

Pauly, D., V. Christensen, S. Guénette, T. J. Pitcher, U. Rasid Sumaila, C. J. Walters, R. Watson, and D. Zeller. 2002. Towards sustainability in world fisheries. Nature, 418: 689-695.

Payne, G., and J. Payne. 2004. Key Concepts in Social Research. SAGE Key Concepts Series. SAGE Publications, London, UK.

Poder Ejecutivo. 1998. Establece aplicación oficial del Código de Conducta Para Pesca Responsable Aprobado por la FAO. Decreto Ejecutivo No 27919. Available from: http://www.pgr.go.cr/Scij (Accessed April 2014). 
2009. Decreto Ejecutivo No 35502-MAG. Reglamento para el Establecimiento de las Áreas Marinas de Pesca Responsable y Declaratoria de Interés Público Nacional de las Áreas Marinas de Pesca Responsable. La Gaceta Nº 191, 10/01/2009. San José, Costa Rica.

Poder Judicial. 2013. Consejo Superior, Circular № 216-2013. Boletín Judicial № 6 , 01/09/2014. San José, CostaRica.

Poder Legislativo. 1994. Ley No 7384. Creación del Instituto Costarricense de Pesca y Acuacultura (INCOPESCA). La Gaceta N ${ }^{\circ}$ 62, 03/29/1994. San José, Costa Rica.

. 2005. Ley N ${ }^{\circ}$ 8436: Ley de Pesca y Acuicultura. La Gaceta No 78, 04/25/2005. San José, Costa Rica.

_2010. Proyecto de Ley $\mathrm{N}^{\circ}$ 17715: Reforma del Artículo 9 de la Ley de Pesca y

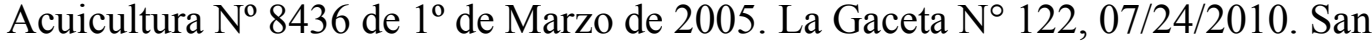
José, Costa Rica.

2013. Proyecto de Ley $\mathrm{N}^{\circ} 18801$ : Prohibiciones sobre artes de pesca ilegales y otras reformas de la Ley $\mathrm{N}^{\circ}$ 8436, Ley de Pesca y Acuicultura, de 25 de Abril de 2005 y derogatoria de los incisos a) y b) del Artículo 47 de la Ley $\mathrm{N}^{\mathrm{o}} 8436$, Ley de Pesca y Acuicultura, de 25 de Abril de 2005. La Gaceta $N^{\circ}$ 134, 07/12/2013. San José, Costa Rica.

Presidencia de la República de Costa Rica. 2012. Report of the Presidential Commission for Marine Governance. San José, Costa Rica. 34 p.

PRETOMA (Programa Restauración de Tiburones y Tortugas Marinas). 2012. Law suit filed against Incopesca's President for failing to adhere to his duties. PRETOMA, Press Release, 02/10/2014. Available from: http://www.pretoma.org/law-suitfiled-against-incopescas-president-for-failing-to-adhere-to-his-duties/ (Accessed March 2014).

_2013. Public call for the creation of new Marine Management Area in Nandayure, Guanacaste, Costa Rica. PRETOMA, Press Release, 11/04/2013. Available from: http://www.pretoma.org/espanol-invitacion-abierta-a-conferencia-solving-theglobal-fisheries-crisis-por-dr-boris-worm/ (Accessed March 2014).

2014. Legislative Assembly's Puntarenas Commission approves sustainable shrimp trawl bill. PRETOMA, Press Release, 02/21/2014. Available from: http://www.pretoma.org/legislative-assemblys-puntarenas-commission-approvessustainable-shrimp-trawl-bill/ (Accessed March 2014). 
Rodgers, E. 2012. Using the institutional grammar tool to understand brownfield action situations. Paper presented at the 2012 Association for Public Policy Analysis \& Management Fall Research Conference. Baltimore, MD, USA.

Ross Salazar, E. 2014. Artes, métodos e implementos de pesca. Fundación MarViva. San José, Costa Rica.

Salas, E., E. Ross, and A. Arias. 2012. Diagnóstico de áreas marinas protegidas y áreas marinas para la pesca responsable en el Pacífico costarricense. Fundación MarViva, San José, Costa Rica.

Schiffrin, D., D. Tannen, and H. E. Hamilton. 2001. The Handbook of Discourse Analysis. Blackwell Publishers. Blackwell Publishers. Malden, MA, USA.

Schneider, A., and H. Ingram. 1993. Social construction of target populations: Implications for politics and policy. American Political Science Review, 87: 334347.

Shrestha-Acharya, R. \& J. T. Heinen. 2009. Emerging policy issues in plant conservation and utilization in Nepal. Himalaya, 26(1-2): 51-54.

Siddiki, S., X. Basurto, and C. M. Weible. 2010. Comparing formal and informal institutions with the institutional grammar tool. Paper presented at the 2010 North American Regional Meeting of the International Society of the Study of the Commons. Arizona State University, Tempe, AZ, USA.

2012. Using the institutional grammar tool to understand regulatory compliance: The case of Colorado aquaculture. Regulation and Governance, 6: 167-188.

Siddiki, S., C. M. Weible, X. Basurto, and J. Calanni. 2011. Dissecting policy designs: An application of the institutional grammar tool. Policy Studies Journal, 39: 79103.

Solano, E. 2005. Ley de Pesca contra pescadores. Ambientico, 139: 12. Ambientico Ediciones, Heredia, Costa Rica.

Solano, H. 2014. Sala IV acoge recurso contra Incopesca por renovar licencias pese a que medida cautelar se lo prohibía. La Nación, 03/28/2014. Available from: http://www.nacion.com/vivir/ambiente/Sala-Incopesca-licencias-cautelarprohibia_0_1405059620.html (Accessed March 2014).

Solís Rivera, V., M. F. Borrás, D. Barguil Gallardo, M. Ochoa, E. Castañeda, and G. Castillo. 2012. Estudio regional sobre las dimensiones sociales en el manejo de áreas marinas protegidas: Casos en Costa Rica, Nicaragua, Honduras y Panamá. International Collective in Support of Fishworkers, Chennai, India. 
Solís Rivera, V., P. Madrigal, and D. Barguil. 2010. Sones que se van al Mar y estrategias de manejo para la sobrevivencia: Un ejemplo de cómo también en Centroamérica se trata de rescatar la identidad cultural de la pesca artisanal. CoopeSoliDar, R.L., San José, Costa Rica.

Sumaila, U. R. and D. Pauly, editors. 2006. Catching more bait: a bottom-up reestimation of global fisheries subsidies (2nd Version). Fisheries Centre Research Reports 14(6). Fisheries Centre, the University of British Columbia, Vancouver, Canada.

Ter-Ghazaryan, D., and J. T. Heinen. 2006. Reserve management during transition: The case of Issyk-kul Reserve, Kyrgyzstan. Environmental Practice, 8(1): 11-22.

Tompkins, E. L., and W. N. Adger. 2004. Does adaptive management of natural resources enhance resilience to climate change? Ecology and Society 9(2): 10 .

Tremblay, M. 1957. The key informant technique: A non-ethnographical application. American Anthropologist, 59:688-701.

Trujillo, P., A. M. Cisneros-Montemayor, S. Harper, and D. Zeller. 2012. Reconstruction of Costa Rica's marine fisheries catches (1950-2008). Working paper 2012-03. Fisheries Centre. The University of British Columbia. Vancouver, Canada.

Turriago, C. S. B. 2013. Contribución de la pesca y la acuicultura a la seguridad alimentaria y el ingreso familiar en Centroamérica. Report. FAO Subregional Office for Mesoamerica and FAO Fisheries and Aquaculture Policy and Economics Division. Available from: http://www.racua.org/es/publicaciones/contribucion-de-la-pesca-y-la-acuiculturaa-la-seguridad-alimentaria-y-el-ingreso-familiar-en-centroamerica/ (Accessed March 2014).

Van Dijk, T. A. 2001. Critical Discourse Analysis. Pages 352-371 in D. Schiffrin, D. Tannen, and H. E. Hamilton, editors. The Handbook of Discourse Analysis. Blackwell Publishers. Blackwell Publishers. Malden, MA, USA.

Vargas, J.A. 1995. The Gulf of Nicoya estuary, Costa Rica: Past, present, and future cooperative research. Helgoländer Meeresuntersuchungen, 49: 821-828.

Vega, M. 1996. Cambios en la sociedad costarricense en las décadas de los ochenta y noventa. Anuario de Estudios Centroamericanos, Universidad de Costa Rica, 22: 129-146.

Víquez, R., and L. M. Sierra. 2005. Pesca artisanal en Tárcoles, Costa Rica. Ambientico, 139: 13-14. Ambientico Ediciones, Heredia, Costa Rica. 
West, P., and D. Brockington. 2006. An anthropological perspective on some unexpected consequences of protected areas. Conservation Biology, 20: 609-616.

Wehrtmann, I. S. and V. Nielsen-Muñoz. 2009. The deepwater fishery along the Pacific coast of Costa Rica, Central America. Latin American Journal of Aquatic Research, 37: 543-554.

Wiber, M., F. Berkes, A. Charles, and J. Kearney. 2004. Participatory research supporting community-based fishery management. Marine Policy, 28: 459-468.

Yandle, T. 2003. The challenge of building successful stakeholder organizations: New Zealand's experience in developing a fisheries co-management regime. Marine Policy, 27: 179-192. 


\section{APPENDICES}

Appendix 1. List of key informants interviewed in Group 2 with their corresponding affiliations and date of interview.

- David Chacón, president and founding member, CoopeTárcoles R.L. (Jul. 9, 2013)

- Jeanette Naranjo, manager, Consorcio Por La Mar, R. L. (Jul. 9, 2013)

- Vivienne Solís-Rivera, managing director and founding member, CoopeSolidar, R.L. (Aug. 3, 2013)

- Berní Marín, Marine Biologist, Department of Research and Development, INCOPESCA (Jul. 23, 2013)

- Jorge Cole, Communities Coordinator, Department of Sciences and Communities, MarViva (Jul. 26, 2013)

- Erick Ross, Sciences Director, Department of Sciences and Communities, Fundación MarViva (Aug. 5, 2013)

- Carmen Castro Morales, Director, Environmental Department, Servicio Nacional de Guardacostas de Costa Rica (Aug. 5, 2013)

- Andrea García Rojas, Ph. D., Marine Biology, Universidad Nacional de Costa Rica, Marine Biology Station (Aug. 7, 2013) 